\title{
Genetic diversity of vector-borne pathogens in spotted and brown hyenas from Namibia and Tanzania relates to ecological conditions rather than host taxonomy
}

Jürgen Krücken ${ }^{1 *}$, Gábor Á. Czirják², Sabrina Ramünke', Maria Serocki²,3, Sonja K. Heinrich 2,3, Jörg Melzheimer ${ }^{3}$, M. Carolina Costa ${ }^{1,4}$, Heribert Hofer ${ }^{5,6,7}$, Ortwin H. K. Aschenborn ${ }^{8}$, Nancy A. Barker ${ }^{9}$, Stefano Capodanno ${ }^{1,10}$, Luís Madeira de Carvalho ${ }^{4}$, Georg von Samson-Himmelstjerna' ${ }^{1}$, Marion L. East ${ }^{11 \dagger}$ and Bettina Wachter ${ }^{3 \dagger}$

\begin{abstract}
Background: Improved knowledge on vector-borne pathogens in wildlife will help determine their effect on host species at the population and individual level and whether these are affected by anthropogenic factors such as global climate change and landscape changes. Here, samples from brown hyenas (Parahyaena brunnea) from Namibia (BHNA) and spotted hyenas (Crocuta crocuta) from Namibia (SHNA) and Tanzania (SHTZ) were screened for vectorborne pathogens to assess the frequency and genetic diversity of pathogens and the effect of ecological conditions and host taxonomy on this diversity.

Methods: Tissue samples from BHNA $(n=17)$, SHNA $(n=19)$ and SHTZ $(n=25)$ were analysed by PCRs targeting Anaplasmataceae, Rickettsia spp., piroplasms, specifically Babesia lengau-like piroplasms, Hepatozoidae and filarioids. After sequencing, maximum-likelihood phylogenetic analyses were conducted.

Results: The relative frequency of Anaplasmataceae was significantly higher in BHNA (82.4\%) and SHNA (100.0\%) than in SHTZ (32.0\%). Only Anaplasma phagocytophilum/platys-like and Anaplasma bovis-like sequences were detected. Rickettsia raoultii was found in one BHNA and three SHTZ. This is the first report of R. raoultii from sub-Saharan Africa. Babesia lengau-like piroplasms were found in $70.6 \%$ of BHNA, 88.9\% of SHNA and $32.0 \%$ of SHTZ, showing higher sequence diversity than B. lengau from South African cheetahs (Acinonyx jubatus). In one SHTZ, a Babesia vogelilike sequence was identified. Hepatozoon felis-like parasites were identified in 64.7\% of BHNA, 36.8\% of SHNA and 44.0\% of SHTZ. Phylogenetic analysis placed the sequences outside the major $\mathrm{H}$. felis cluster originating from wild and domestic felids. Filarioids were detected in $47.1 \%$ of BHNA, $47.4 \%$ of SHNA and $36.0 \%$ of SHTZ. Phylogenetic analysis revealed high genetic diversity and suggested the presence of several undescribed species. Co-infections were frequently detected in SHNA and BHNA (BHNA median 3 pathogens, range 1-4; SHNA median 3 pathogens, range 2-4) and significantly rarer in SHTZ (median 1, range 0-4, 9 individuals uninfected).
\end{abstract}

\footnotetext{
${ }^{*}$ Correspondence: juergen.kruecken@fu-berlin.de

${ }^{\dagger}$ Marion L. East and Bettina Wachter contributed equally to this work

${ }^{1}$ Institute for Parasitology and Tropical Veterinary Medicine, Freie Universität Berlin, Berlin, Germany

Full list of author information is available at the end of the article
}

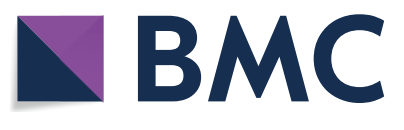

(c) The Author(s) 2021. This article is licensed under a Creative Commons Attribution 4.0 International License, which permits use, sharing, adaptation, distribution and reproduction in any medium or format, as long as you give appropriate credit to the original author(s) and the source, provide a link to the Creative Commons licence, and indicate if changes were made. The images or other third party material in this article are included in the article's Creative Commons licence, unless indicated otherwise in a credit line to the material. If material is not included in the article's Creative Commons licence and your intended use is not permitted by statutory regulation or exceeds the permitted use, you will need to obtain permission directly from the copyright holder. To view a copy of this licence, visit http://creativeco mmons.org/licenses/by/4.0/. The Creative Commons Public Domain Dedication waiver (http://creativecommons.org/publicdomain/ zero/1.0/) applies to the data made available in this article, unless otherwise stated in a credit line to the data. 
Conclusions: The frequencies of all pathogens groups were high, and except for Rickettsia, multiple species and genotypes were identified for each pathogen group. Ecological conditions explained pathogen identity and diversity better than host taxonomy.

Keywords: Wildlife parasites, Vector-borne diseases, Tick-borne diseases, Carnivores, Hyenas, Pathogen ecology

\section{Background}

Vector-borne pathogens can cause severe diseases in carnivores, such as leishmaniasis [1], babesiosis [2,3] or cardiopulmonary dirofilariasis $[4,5]$. Whereas canine vector-borne diseases have received much attention during the past decades, feline diseases were less often investigated [6-9]. Even less investigated are pathogens of wild carnivores, which are often only addressed if wild carnivore populations are important reservoirs of either severe diseases of closely related domestic animals or zoonotic pathogens. For example, Babesia rossi has its natural reservoir in wild canids such as side-striped jackals (Canis adustus) and African wild dogs (Lycaon pictus) and causes hyper-virulent babesiosis in domestic dogs in sub-Saharan Africa [10]. Important zoonotic vectorborne pathogens of carnivores with reservoirs in wildlife are Leishmania infantum, Dirofilaria immitis and Dirofilaria repens [11]. Studies on vector-borne pathogens of wild carnivores focus on temperate and Mediterranean European regions, the United States and South Africa, so current knowledge on vector-borne pathogens in other tropical and subtropical regions and their impact on humans, domestic species and wildlife is limited [12-14]. Furthermore, increased contact between domestic animals and wildlife associated with human degradation of natural habitats can pose a health threat to wildlife populations, since domestic animals might serve as reservoirs for and amplifiers of vector-borne pathogens transmitted to wildlife [15].

Our study aimed to use molecular techniques to determine the presence, identity and diversity of vector-borne pathogens in two species in the family Hyaenidae to investigate the importance of host species and sampling location and habitat [16] with respect to infection. For this purpose, we collected blood and tissue samples from brown hyenas (Parahyaena brunnea Thunberg 1820) in Namibia and from spotted hyenas (Crocuta crocuta Erxleben 1777) in Namibia (Southern Africa) and Tanzania (East Africa) from three major habitats which vary in ecological characteristics and the kind of and the degree to which human activities affect vector and host populations. Namibian livestock farmland rarely burns, and contains livestock, companion animals, artificial water sources and possibly cattle dips to control ticks. Etosha National Park is not regularly burnt and has artificial waterholes. In the Serengeti National Park in Tanzania, many natural processes are intact but it is subjected to annual fire 'management' which might decrease populations of vectors such as ticks, thereby affecting transmission of tick-borne parasite infections in hyenas. We thus compared differences in the relative frequency of pathogen infections between brown and spotted hyenas within one geographic region (Namibia) and in one hyena species (spotted hyena) between two regions, which differed in the type and scale of human activities.

The brown hyena is listed as "Near Threatened" by the International Union for Conservation of Nature (IUCN), and its range is limited to arid and semi-arid regions in southern Africa [17]. Brown hyenas prey on small mammals including livestock, and also scavenge on carcasses of livestock and large wild herbivores, including those killed by other carnivores $[18,19]$. We screened samples from brown hyenas that inhabited livestock grazing areas, where they were likely to encounter vectors of pathogens that infect livestock, companion animals associated with farms, and wildlife species that inhabit livestock farmland [20, 21]. Brown hyenas form small clans comprising individual females with their offspring, sometimes belonging to different age classes [22]. All females within a clan reproduce and mate with nomadic or immigrant males [18]. Clans hold large territories between 235 and $480 \mathrm{~km}^{2}$ [22].

The spotted hyena is listed as of "Least Concern" by IUCN. The spotted hyena samples in our study came from two separate populations in large protected areas, Etosha National Park (NP) in Namibia, which covers 22,270 $\mathrm{km}^{2}$, and Serengeti NP in Tanzania, which covers $14,763 \mathrm{~km}^{2}$. In Etosha NP, clan sizes are an order of magnitude smaller and clan territories an order of magnitude larger [23] than those in the Serengeti NP [24, $25]$. In both populations, clans keep their cubs in communal dens. Communal den areas are social centres for clans, hence important locations for the transmission of pathogens [26-28]. The number of cubs occupying a den can increase the prevalence of vector-borne pathogens, as shown for the helminth Dipylidium sp. [29]. This suggests that individuals in the large 'Serengeti' clans should be more prone to pathogen infection than those in small 'Etosha' clans. Spotted hyenas with larger lifetime ranges are more likely to encounter pathogens [30] than those with more limited ranges. As a result of the migratory movement of herbivores in both Etosha and Serengeti 
NPs, adults in both populations forage over extensive areas [31, 32]. Etosha NP receives annual rainfall of $350 \mathrm{~mm}$, far lower than the Serengeti NP with $1200 \mathrm{~mm}$ in the north-west and $500 \mathrm{~mm}$ in the south-east [32, 33], which suggests that parasite vectors with poor survival in arid conditions with high daytime temperatures may be less abundant in Etosha during the dry season. Etosha NP (unlike the Serengeti NP) has artificial waterholes, which attract water-dependent species [34]. This is likely to increase the abundance of vectors such as ticks in these locations in the vicinity of waterholes, and also vectors with life stages that require an aquatic environment, such as mosquitoes, which could breed throughout the dry season. In the Serengeti NP, large areas are burnt soon after the end of the long rains, which is not the case in Etosha NP. 'Early burning' should decrease tick abundance in burnt areas [35] and thereby reduce the transmission of tick-borne parasites. Hence infection with tick-borne parasites should be lower in spotted hyenas in the Serengeti NP than in Etosha NP. Brown hyenas in farmland that is not burnt and contains livestock, companion animals, wild herbivores and artificial water supplies for livestock may be expected to encounter the largest diversity of vectors and have the highest diversity of parasites.

This study focused on several vector-borne bacteria (Anaplasmataceae, Rickettsia spp.), Apicomplexa (Hepatozoon spp., Babesia spp.) and filarioid nematodes (Onchocercidae). Ticks (Ixodida) are the vectors for all Babesia species and all Hepatozoon species of carnivores and for most Anaplasmataceae and Rickettsia spp. [36]. In contrast, the vector spectrum of Onchocercidae is very broad, and different parasite species use different vectors including mosquitoes (Culicidae), black flies (Simuliidae), biting midges (Ceratopogonidae), horse flies (Tabanidae), fleas (Siphonaptera), louse flies (Hippoboscidae), lice (Phthiraptera), ticks and other mites such as Macronyssidae [36-40]. These parasites have stages that circulate in peripheral blood and can be readily detected by polymerase chain reaction (PCR). Currently, available information on vector-borne pathogens is sparse for both species of hyenas, particularly regarding bacterial pathogens. As far as we know, infection with Anaplasmataceae has not been previously reported in either brown or spotted hyenas. There are two studies where samples from brown and spotted hyenas from Zambia, Namibia and South Africa tested negative for Ehrlichia [41, 42]. For Rickettsia spp. there is a single serological study which stated that one of three investigated spotted hyenas was positive for antibodies against Rickettsia akari in a complement fixation assay at a dilution of 1:10 but not at a dilution of 1:40 [43]. No antibodies were detected against Rickettsia conori, Rickettsia mooseri or Rickettsia burneti [43].
Spotted hyenas are often infected with Hepatozoon sp. [44]. In the Serengeti NP, these parasites were highly similar or identical to Hepatozoon felis [45]. In Zambia, spotted hyenas were positive for both Hepatozoon canis and $H$. felis [41]. Williams et al. [41] also identified a Babesia sp. in spotted hyenas very similar to Babesia lengau which had been previously described in cheetahs (Acinonyx jubatus) in Namibia [46]. This finding was confirmed in a recent study from Namibia and South Africa for brown and spotted hyenas [42]. Babesia lengau or very similar Babesia spp. have been associated with severe disease in domestic cats and a sheep [47], which suggests that all the apicomplexan blood parasites described for brown and spotted hyenas might be a potential health risk to wild as well as domestic animals.

In the Turkana district in northern Kenya, two spotted hyenas were reported to be positive for Acanthocheilonema dracunculoides (syn. Dipetalonema dracunculoides) [48]. This parasite was also found in two domestic dogs in the same area and in domestic dogs in Namibia [49]. In both studies the parasites were identified either by morphometry of microfilaria [48] or by acid phosphatase staining [49], and therefore the exact species identification should be considered as doubtful without morphological data on adult parasites or DNA sequence data. Third-stage infective larvae with a morphology in accordance with A. dracunculoides were found in Hippobosca longipennis louse flies in Kenya [38].

In summary, at least four vector-borne parasites previously identified in brown hyenas (H. canis, H. felis, B. lengau and $A$. dracunculoides) are also potential pathogens in domestic animals. The present study thus aimed to identify vector-borne pathogens in the groups Anaplasmataceae, Rickettsia sp., Hepatozoon sp., Piroplasmida and Onchocercidae in brown hyenas from Namibia and spotted hyenas from Namibia and Tanzania.

\section{Methods}

Study area, sample collection and DNA extraction

In Namibia, 16 whole blood samples and one liver sample were collected from brown hyenas from farmland in central and north-central Namibia $(n=15)$ and farmland adjacent to the Skeleton Coast NP in north-west Namibia $(n=2)$. From spotted hyenas, 14 whole blood samples and five buffy coat samples were collected from the Etosha NP $(n=18)$ and the farmland in north-central Namibia ( $n=1$, Additional file 1: Table S1). The hyenas were captured, anaesthetised and sampled as previously described [50-52], except for one brown hyena shot by a farmer because he judged the animal to be a threat to his livestock. Samples from brown and spotted hyenas were stored in liquid nitrogen containers or at $-20^{\circ}$ until transport to Germany. In Germany, samples were 
stored at $-80^{\circ} \mathrm{C}$ before DNA extraction using the GENIAL $^{\circledR}$ First-DNA all-tissue kit. Blood samples from spotted hyenas $(n=25)$ were collected in the Serengeti NP in northern Tanzania from carcasses of recent vehicle accidents and predation by lions (Panthera leo), or from animals anaesthetised for the removal of wire snares [31]. These samples were stored at $-20{ }^{\circ} \mathrm{C}$ until transport to Germany. DNA was extracted using the Maxwell ${ }^{\circledR} 16$ LEV Blood DNA Kit and the Maxwell ${ }^{\circledR} 16$ instrument (Promega). All DNA samples were stored at $-20{ }^{\circ} \mathrm{C}$ or $-80{ }^{\circ} \mathrm{C}$ until used for this study.

\section{PCR amplifications and sequencing}

PCR was performed using either Phusion Hot Start II High-Fidelity DNA Polymerase or Maxima Hot Start Taq DNA Polymerase (both Thermo Scientific). All reactions except for the one targeting Hepatozoon spp. were conducted with Phusion enzyme in a $20 \mu \mathrm{L}$ reaction volume consisting of $0.2 \mathrm{mM}$ of deoxynucleoside triphosphates (dNTPs), $0.25 \mu \mathrm{M}$ of each primer, $0.02 \mathrm{U} / \mu \mathrm{L}$ of Phusion Hot Start II High-Fidelity DNA Polymerase and $2 \mu \mathrm{L}$ of template DNA in $1 \times$ Phusion HF Buffer. The Hepatozoon PCR was performed in $25 \mu \mathrm{L}$ reaction volume consisting of $0.2 \mathrm{mM}$ dNTPs, $0.3 \mu \mathrm{M}$ of each primer, $0.04 \mathrm{U} / \mu \mathrm{L}$ Maxima Hot Start Taq DNA Polymerase, $2.5 \mathrm{mM} \mathrm{MgCl}$ and $2 \mu \mathrm{L}$ of template DNA in $1 \times$ Maxima Hot Start PCR Buffer. PCR-specific denaturation and annealing temperatures and times used for the different PCR steps are provided in Additional file 2: Table S2. The number of PCR cycles was 40 except for the PCR to detect Anaplasmataceae, for which 50 cycles were conducted. For negative controls, nuclease-free water was used instead of template DNA in all PCR runs. As positive controls, plasmid DNA containing the respective amplicon was used. Primers used for pathogen-specific PCRs were derived from previous publications [53-60] and are provided in Additional file 2: Table S2.

A PCR specific for $B$. lengau-like parasites was developed. Primers were designed to match $B$. lengau, $B$. lengau-like parasites from hyenas and closely related parasites such as B. conradae and Babesia duncani. PCR conditions were optimised using samples known to be positive for $B$. lengau-like parasites and negative for Hepatozoon spp. or the classical Babesia species Babesia vogeli and Babesia canis. Evaluation of specificity was performed with samples negative for $B$. lengau-like piroplasms but positive for B. canis, B. vogeli or $H$. canis. The optimised PCR contained $0.25 \mu \mathrm{M}$ of each primer, $0.2 \mathrm{mM}$ dNTPs, $0.02 \mathrm{U} / \mu \mathrm{l}$ Phusion Hot Start II HighFidelity DNA Polymerase and $2 \mu$ template DNA in $20 \mu \mathrm{l}$ Phusion HF buffer. Primer sequences are also provided in Additional file 2: Table S2. After an initial denaturation at $98{ }^{\circ} \mathrm{C}$ for $30 \mathrm{~s}, 40$ cycles of denaturation at $98^{\circ} \mathrm{C}$ for $20 \mathrm{~s}$, annealing at $65{ }^{\circ} \mathrm{C}$ for $30 \mathrm{~s}$ and elongation at $72{ }^{\circ} \mathrm{C}$ for $30 \mathrm{~s}$ were conducted. Finally, reactions were incubated at $72{ }^{\circ} \mathrm{C}$ for $5 \mathrm{~min}$. As positive control, DNA from a $B$. lengau-like blood sample was chosen.

For further characterisation of parasites, some amplification products from samples that showed positive results were purified with the DNA Clean \& Concentrator $^{\circledR}-5$ Kit (Zymo Research Corporation, Irvine, USA) according to the manufacturer's instructions. If available, at least five samples were chosen for each of the three groups of hyenas, and very weak bands were avoided whenever possible. Then, purified PCR products were cloned into the StrataClone blunt-end PCR cloning vector 'pSC-B-amp/kan' supplied in the StrataClone Blunt PCR cloning kit (Agilent Technologies, CA, USA) or the TOPO TA Cloning Kit for Sequencing (Thermo Scientific), and recombinant plasmid vectors were transformed into Solopack1 (Agilent Technologies, CA, USA) or One Shot TOP10 (Thermo Scientific) competent cells according to the manufacturer's instructions. Plasmid DNA was isolated using the EasyPrep1Pro Plasmid Mini Prep Kit (Biozym, Oldendorf, Germany), and clones with inserts were sequenced by LGC Genomics (Berlin, Germany).

\section{Sequence analyses}

Initially, sequences were compared to the NCBI GenBank $^{\text {TM }}$ database using BLASTn (https://blast.ncbi.nlm. nih.gov/Blast.cgi) reporting the percentage of identical nucleotides in the alignment [61]. If sequences in Gen$\mathrm{Bank}^{\mathrm{TM}}$ were more than $98 \%$ identical to our sequences, we considered this pathogen to belong to the species referred to in GenBank. If there was not a closely matched sequence available, the sequence was considered to belong to a species for which the respective target sequence had not been deposited in GenBank. In these cases, phylogenetic analyses were conducted to identify the closest known relatives of the pathogen.

\section{Phylogenetic analyses}

All rRNA sequences were aligned using MAFFT with the Q-INS-i option $[62,63]$. For $18 \mathrm{~S}$ rRNA regions, the "Try to align gappy regions anyway" option was used (command line: mafft-qinsi-maxiterate 2-reorder input), while for internal transcribed spacer (ITS) sequences the "Leave gappy regions" option was chosen (command line: mafft-qinsi-maxiterate 2-reorder-leavegappyregion input). Identification of best substitution models and calculation of best phylogenetic tree were both performed using ModelFinder [64] and IQ-TREE [65] on the IQTREE web server [66]. ModelFinder was set to autoselect the optimal substitution model and to also consider FreeRate heterogeneity models. Ultrafast bootstrapping [67] 


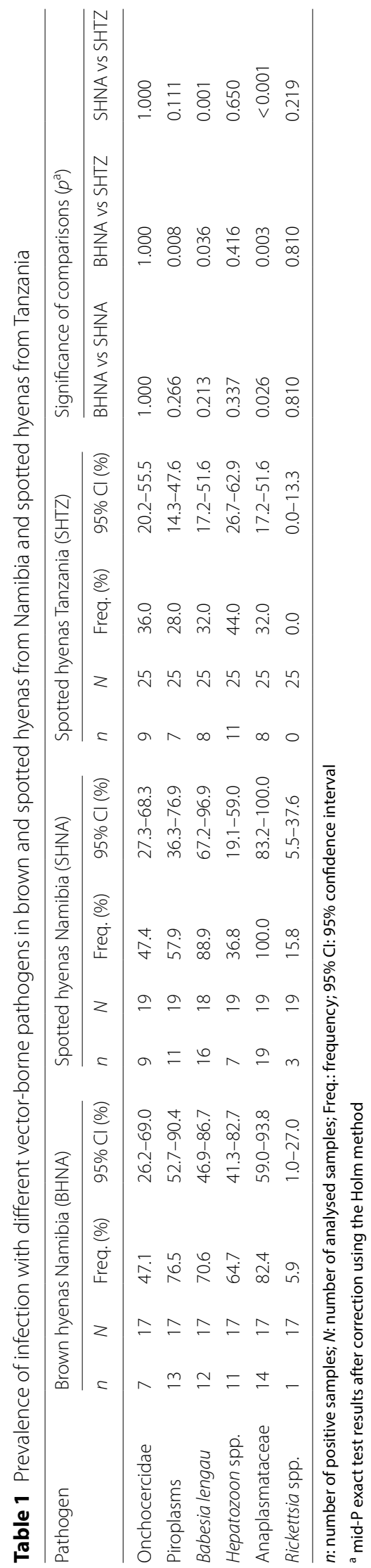


and Shimodaira-Hasegawa approximate likelihood ratio tests (SH-aLRTs) [68] were both performed with 1000 replicates. The final command line was: path_to_iqtree-s iqtree_Alignment.phy-st DNA -m TESTNEW-bb 1000alrt 1000. Trees were visualised using FigTree version 1.4.4.

\section{Statistical analyses}

For relative frequencies of pathogens, 95\% confidence intervals (CIs) were calculated as Wilson score values using the binom.wilson function of the $\mathrm{R}$ package epitools 0.5-10 in $R$ version 3.5.3. Differences in relative frequencies were judged to be significant with the help of the mid-P exact test conducted with the tab2by2. test function implemented in epitools. For all comparisons between the three groups of hyenas, $p$ values were adjusted using the p.adjust method in $\mathrm{R}$ applying the "Holm" correction method. The number of pathogens simultaneously infecting an individual (co-infections) was compared between brown hyenas from Namibia (BHNA), spotted hyenas from Namibia (SHNA) and spotted hyenas from Tanzania (SHTZ) using a KruskalWallis test followed by Dunn's post hoc test in GraphPad Prism 5.03.

\section{Results}

Relative frequency and identification of Anaplasmataceae A PCR previously shown to detect Anaplasma spp., Ehrlichia spp. and Neoehrlichia spp. was positive for $82.4 \%, 100.0 \%$ and $32.0 \%$ of BHNA, SHNA and SHTZ, respectively (Table 1). All relative infection frequencies were significantly different from each other (BHNA vs SHNA: $p=0.026$, BHNA vs SHTZ: $p=0.003$, SHNA vs SHTZ: $p<0.001)$. Sequence analyses for 22 out of 24 sequenced samples from all three hyena groups $(7 / 7$ BHNA, 10/10 SHNA, 5/7 SHTZ) revealed 98-100\% identity with Anaplasma platys, Anaplasma phagocytophilum and Anaplasma camelii sequences (e.g., accession no. MN453481), which were identical in the amplified 16S rRNA gene fragments. For two SHTZ samples (I744 and C004), sequences were $98.1 \%$ identical with Anaplasma bovis (e.g., accession no. MH255940).

\section{Relative frequency and identification of Rickettsia spp.}

A gltA PCR was positive for one BHNA (5.9\%), three SHNA (15.8\%) and none of the SHTZ samples (Table 1), with no significant differences between the groups. Sequences of all four positive samples were $100 \%$ identical to Rickettsia raoultii (e.g., GenBank accession no. MN550896). Since the number of positive samples was low and the identified species was the same as the one used as positive control, the positive control plasmids obtained by cloning from German Dermacentor reticulatus tick samples [69] were re-sequenced. All sequences from Namibian samples consistently differed by a single nucleotide from the positive control, excluding the possibility of a false-positive diagnosis.

\section{Relative frequency and phylogenetic position of identified Hepatozoon spp.}

A PCR targeting the 18S rRNA of Hepatozoon spp. was conducted for all samples. Frequencies of infection with Hepatozoon spp. were $64.7 \%, 36.8 \%$ and $44.0 \%$ for BHNA, SHNA and SHTZ, respectively (Table 1). Relative frequencies did not differ significantly between the three groups (mid-P exact test).

BLASTn analyses identified as best hits either the sequence KY511259 (97.1\% to $99.5 \%$ identity) or KC138533 (98.4\% to $99.4 \%$ identity), both annotated in GenBank as $H$. felis derived from domestic cats. Since the identity of some sequences to the best hit from $\mathrm{H}$. felis was below 99\%, a phylogenetic analysis was conducted. This analysis did not confirm that the sequences identified from brown or spotted hyenas belonged to $H$. felis. Although the phylogram in Fig. 1 is characterised by generally low node support values, none of the 17 sequences from hyenas (five BHNA, six SHNA, six SHTZ) was included in the large cluster of 79 sequences assigned to the taxon $\mathrm{H}$. felis (designated as $\mathrm{H}$. felis sensu stricto for the discussion). The GenBank entries KY511259 and KC138533 were also not included in this cluster.

\section{Relative frequency and phylogenetic position of identified Piroplasmida}

In a first step, a published pan-piroplasm PCR [55, 58] was used to analyse all hyena samples. In this PCR, $76.5 \%, 57.9 \%$ and $28.0 \%$ of the BHNA, SHNA and SHTZ samples were positive, respectively (Table 1 ). The relative frequency of infection in SHTZ was significantly lower than in BHNA ( $p=0.008$, mid-P exact test); there was no significant difference between the other paired comparisons (Table 1).

Sequence analyses of PCR products revealed that one out of 15 samples represented Sarcocystis spp. With the exception of a single $B$. vogeli-like sequence ( $96.9 \%$ identity with MK830995), all piroplasm sequences showed $94.4 \%$ to $97.5 \%$ identity with B. lengau or B. lengau-like parasites $(n=13)$.

The new PCR suitable for detecting the B. lengau/B. conradae group was applied to all samples except for four SHNA samples from which no DNA was left (this PCR was conducted as the last one). Since sequence data for three of these samples for the pan-piroplasm PCR confirmed the presence of $B$. lengau-like parasites, these samples were considered to be positive for this parasite, whereas the only positive sample in the pan-piroplasm 


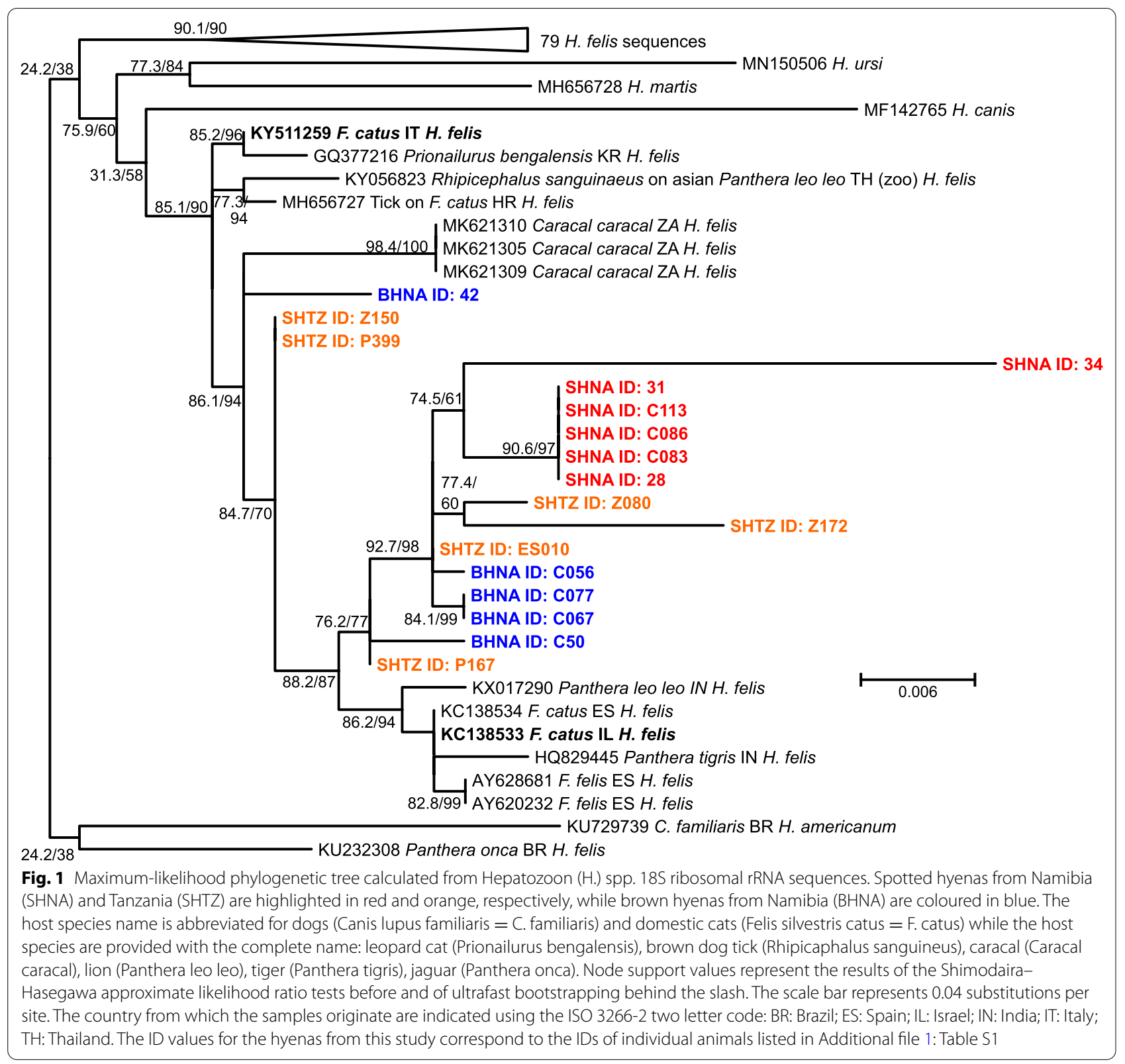

PCR which was not sequenced was considered to have an unidentified status. Relative frequencies of $B$. lengaulike parasites in BHNA, SHNA and SHTZ were 70.6\%, $88.9 \%$ and $32.0 \%$, respectively (Table 1 ). The relative frequency of infection in SHTZ was significantly lower than that in SHNA ( $p=0.001$, mid-P exact test) and BHNA $(p=0.036)$. There was no significant difference between the hyena species in Namibia (Table 1).

Since the sequences obtained from the pan-piroplasm PCR are quite short, no analysis over all piroplasms was conducted. Instead, two separate analyses were conducted for the $B$. lengau-and the $B$. vogeli-like sequences. For $B$. lengau-like piroplasms, similar sequences in
GenBank were selected on the basis of high identity in BLASTn. For the phylogram, only one selected sequence of Babesia vesperuginis (B. conradaelduncanillengau group) was included. For the outgroup, sequences of Babesia leo, Babesia felis, Babesia annae and Babesia microti (all belonging to the Babesia microti-like group) were used. The phylogram in Fig. 2 presents the results of the maximum-likelihood phylogenetic analysis and reveals that all sequences from hyenas from the present study as well as from a spotted hyena from Zambia form a single clade (B. lengau-like ex Hyaenidae). This clade shows only moderate statistical support and appears to be quite divergent (Fig. 2). The hyena parasites were 


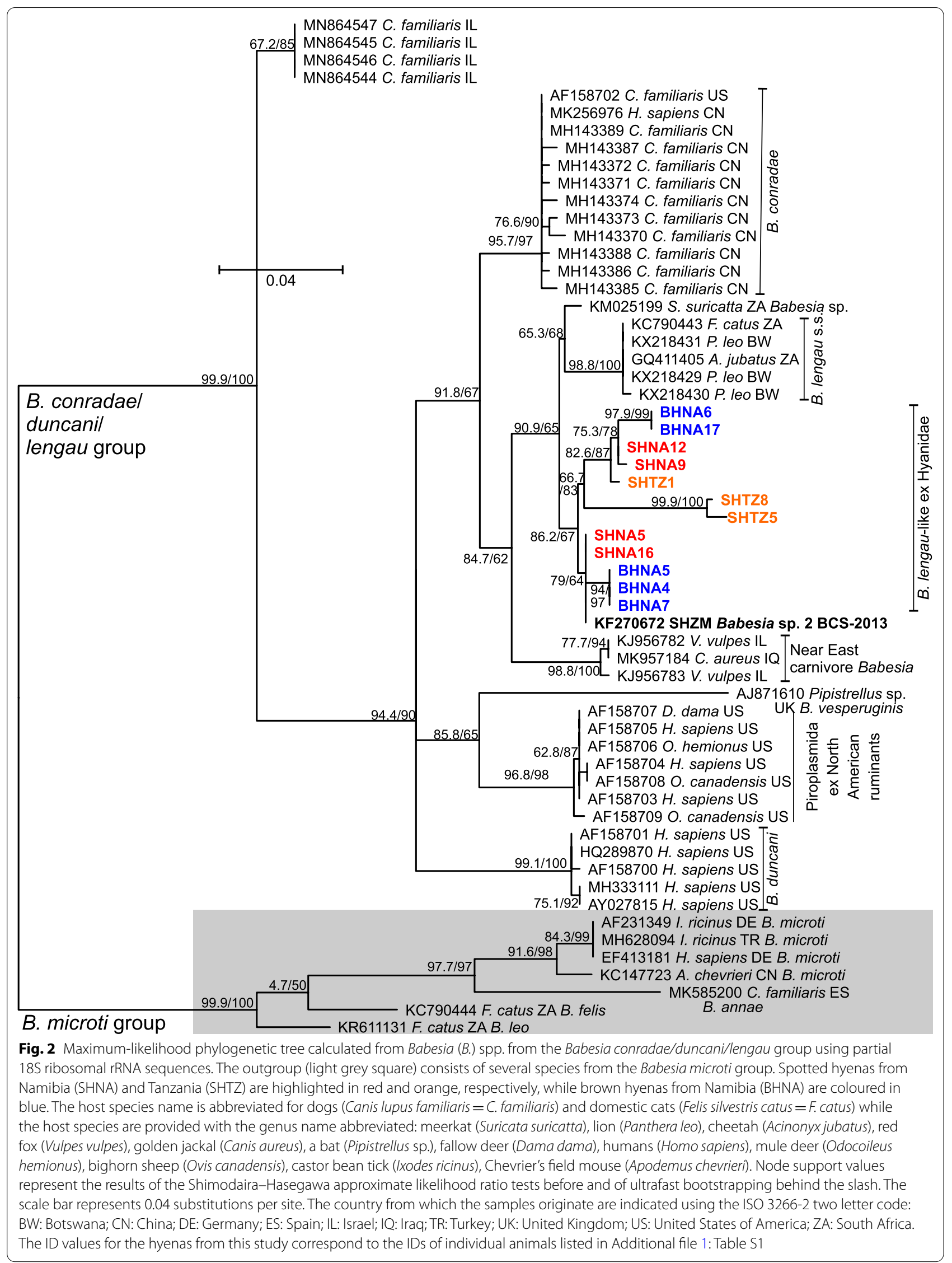


closely related to a homogeneous and strongly supported group of B. lengau s.s. from wild and domestic felines from southern Africa and to a single sequence reported from a meerkat (Suricata suricatta) from Zambia. In comparison to $B$. lengau-like ex Hyaenidae, all other groups of $B$. conradae/duncani/lengau showed much lower intra-group variability, suggesting that $B$. lengaulike ex Hyaenidae might consist of more than one species (Fig. 2).

To identify the phylogenetic position of the single $B$. vogeli-like sequence identified in a SHTZ, all B. vogeli, B. canis, B. rossi, Babesia presentii and Babesia varunai sequences with a query coverage of at least $98 \%$ were included. These five species were previously considered to represent subspecies of $B$. canis, but at least the previous subspecies $B$. canis canis, $B$. canis vogeli and $B$. canis rossi are now considered to be independent species (Solano-Gallego and Baneth, 2011). As an outgroup, sequences of Babesia gibsoni, Babesia divergens, Babesia odocoilei, and Babesia venatorum (all Babesia s.s.) were chosen. The vast majority of the $B$. vogeli sequences form a single cluster with very little variability (Fig. 3). Two sequences annotated as $B$. vogeli from domestic dogs and the sequence from the SHTZ were located closer to the origin of the tree than the large cluster. The three sequences did not cluster with each other. They were in principle in a similar position as (i) B. presentii in comparison to B. canis and (ii) B. varunai in comparison to $B$. rossi and might represent either additional species or subspecies of B. vogeli (Fig. 3).

\section{An undescribed species of the genus Sarcocystis?}

The samples were not systematically screened for the presence of Sarcocystis, since this parasite is only transiently present in peripheral blood. Because of crossreactivity of the pan-piroplasm PCR, a single sequenced clone obtained from a SHNA represented a Sarcocystis sequence that was most similar (95.9\%) to Sarcocystis sp. isolate S.MonN1Oc14 amplified from muscle tissue of a white-tailed mongoose (Ichneumia albicauda) from South Africa. The second best matching species was Sarcocystis nesbitti, a zoonotic species from Southeast Asia assumed to use pythons as the definitive and primates as intermediate hosts. Since the $18 \mathrm{~S}$ rRNA target is highly conserved, and pairwise sequence identity between 15 sequences annotated as $S$. nesbitti was always $>97.5 \%$, it is likely that the new sequence is a species not previously represented in GenBank.

Phylogenetic analyses confirmed that the parasite, in the following designated as Sarcocystis sp. ex Crocuta crocuta, is in a sister position to Sarcocystis sp. isolate S.MonN1Oc14 from I. albicauda (Fig. 4). The second closest relative was not $S$. nesbitti but Sarcocystis singaporensis, another species which uses pythons as definitive and rodents as intermediate hosts. Grouping of $S$. singaporensis with the two species using SHNA and whitetailed mongoose from southern Africa as intermediate hosts had only moderate statistical support (Fig. 4). The only other Sarcocystis species described using carnivores from South Africa as intermediate hosts, also from a white-tailed mongoose, was not closely related to Sarcocystis sp. ex Crocuta crocuta (Fig. 4).

\section{Relative frequency and phylogenetic position of the identified Onchocercidae}

The ITS-2 PCR for filarioid nematodes revealed high relative frequencies of $47.1 \%, 47.4 \%$ and $36.0 \%$ in BHNA, SHNA and SHTZ, respectively (Table 1). None of the comparisons between relative frequencies in the three groups was significant. These results suggest that transmission of filarioids is similar across study sites in Namibia and Tanzania.

Sequence data were obtained by choosing five, five and nine samples from BHNA, SHNA and SHTZ, respectively, followed by cloning and sequencing a single clone per sample. All revealed reasonable identity (82.9-86.2\%) in BLASTn analyses to Acanthocheilonema spp. sequences in GenBank. These identities were much lower than would be expected for intraspecific comparisons. Identity between the new sequences was between 79.3 and 100\%. Maximum-likelihood phylogenetic analysis was conducted by including all Acanthocheilonema sequences from GenBank as well as all 19 sequences obtained in the present study. We did not use any proper

\footnotetext{
(See figure on next page.)

Fig. 3 Maximum-likelihood phylogenetic tree calculated from Babesia (B.) spp. from the Babesia canis group using partial 18S ribosomal rRNA sequences. The outgroup (light grey square) consists of several species from the Babesia sensu stricto group. Spotted hyenas from Namibia (SHNA) and Tanzania (SHTZ) are highlighted in red and orange, respectively, while brown hyenas from Namibia (BHNA) are coloured in blue. The host species name is abbreviated for dogs (Canis lupus familiaris $=$ C. familiaris) and domestic cats (Felis silvestris catus = F. catus) while the brown dog tick (Rhipicephalus sanguineus) is provided with the complete name. Node support values represent the results of the Shimodaira-Hasegawa approximate likelihood ratio tests before and of ultrafast bootstrapping behind the slash. The scale bar represents 0.02 substitutions per site. The country from which the samples originate are indicated using the ISO 3266-2 two letter code: AR: Argentina; BR: Brazil; Cl: Cote d'Ivoire; CN: China; DZ: Algeria; EG: Egypt; ES: Spain; FR: France; IN: India; KN: Saint Kitts and Nevis; NG: Nigeria; JP: Japan; PY: Paraguay; RO: Romania; RU: Russia, TW: Taiwan; US: United States of America; VE: Venezuela; ZM: Zambia. The ID values for the hyenas from this study correspond to the IDs of individual animals listed in Additional file 1: Table S1
} 


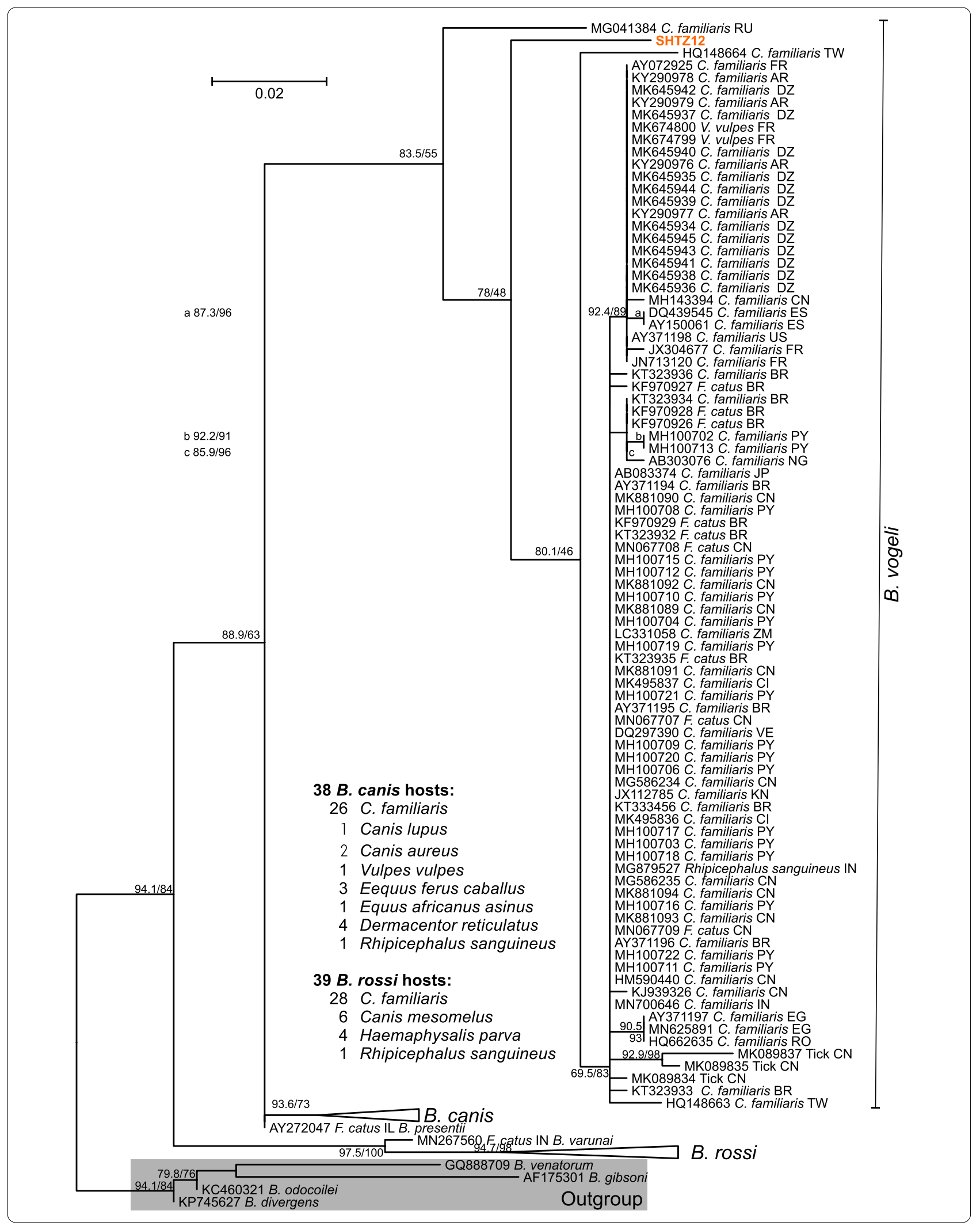




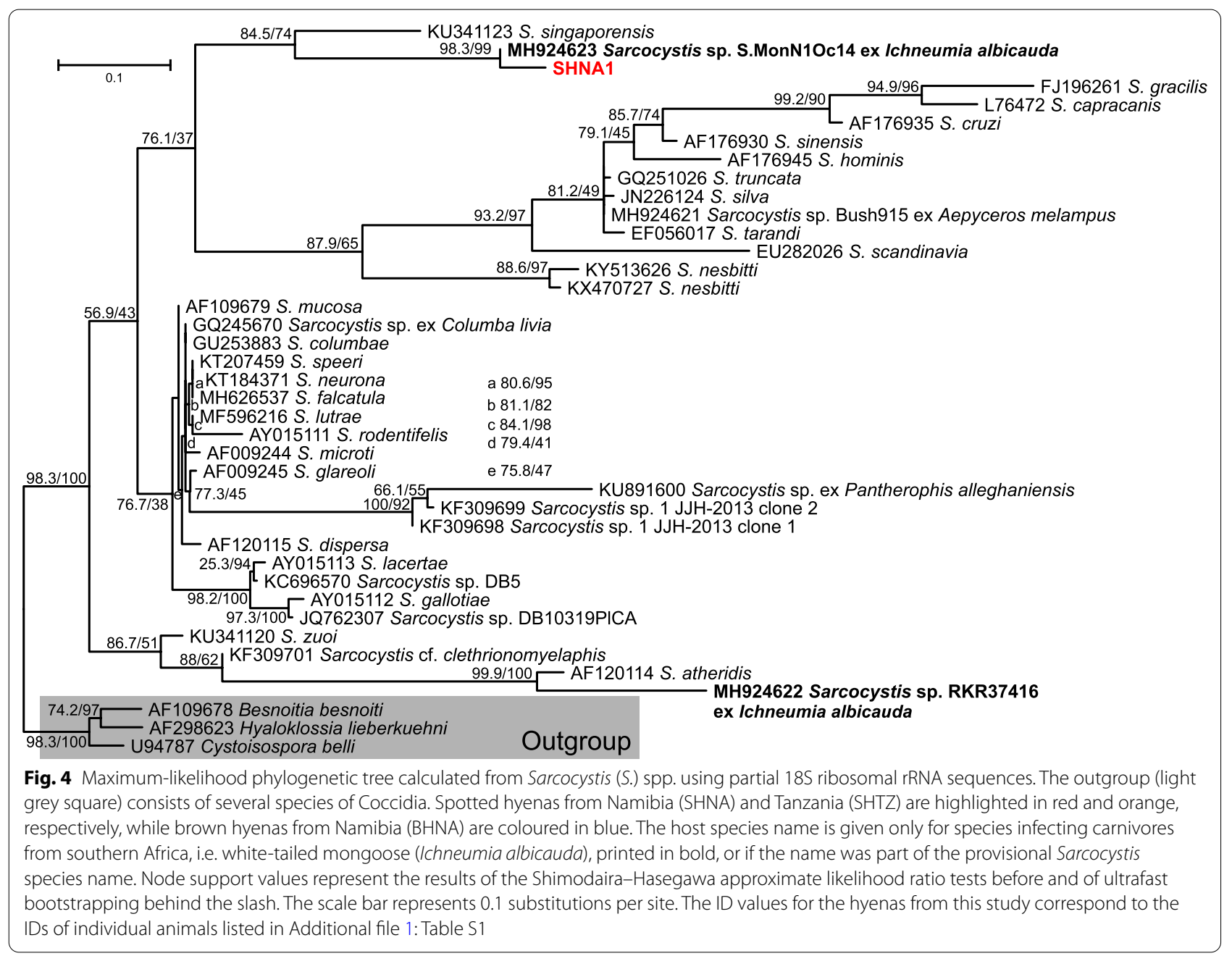

outgroups since there was virtually no sequence similarity of the ITS-2 region to members of the Onchocercidae outside the genus Acanthocheilonema. Therefore, the phylogram presented in Fig. 5 shows an unrooted tree. Because of its low intraspecific variability, A. dracunculoides was arbitrarily chosen as outgroup to improve visualisation. The inner nodes of the tree show only low to moderate statistical support; the phylogeny of the different groups has thus to be confirmed using additional markers. Nevertheless, the tree contains three strongly supported groups with low sequence variability and a considerable distance to other operational taxonomic units: A. dracunculoides from domestic dogs and domestic cats, the seal heartworm Acanthocheilonema spirocauda from earless seals (Phocidae) and four sequences exclusively detected in BHNA and representing four of five BHNA sequences (designated as Acanthocheilonema sp. ex Parahyaena brunnea in Fig. 5). These groups most likely represent valid species. The widely accepted species Acanthocheilonema reconditum was statistically highly supported, although intraspecific variability was very high, suggesting that sequences might have originated from more than one (cryptic) species. Most closely related to $A$. reconditum were two sequences reported from domestic dogs from northern India (Kashmir) and Iran labelled $A$. reconditum-like in Fig. 5. Two sequences from spotted hyenas from Namibia and Tanzania labelled Acanthocheilonema sp. ex Crocuta crocuta formed a separate group, but the length of the branches connecting these sequences was rather high and the statistical support for this group was only moderate. Most sequences obtained from spotted hyenas were located in the cluster labelled Acanthocheilonema sp.ex Hyaenidae (Fig. 5). It contains sequences obtained from spotted hyenas of both Namibian and Tanzanian origin and one sequence from a brown hyena in Namibia. The support for this cluster 


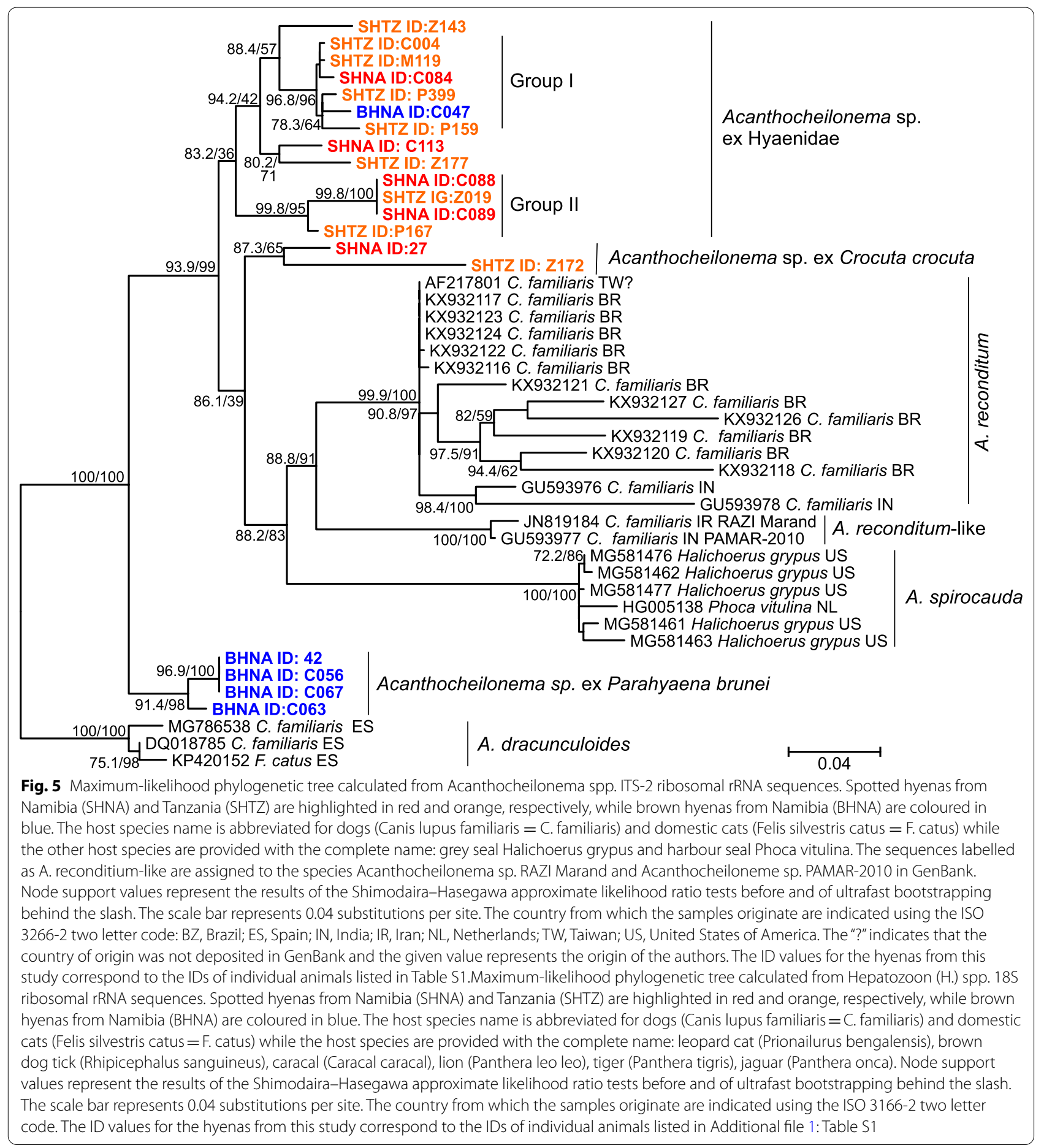

was low and variability was moderately high. There are two subgroups in this cluster containing six and four out of 13 Acanthocheilonema sp. ex Hyaenidae sequences, which show high statistical support (Group I and Group II in Fig. 5). It remains unclear whether this is of any taxonomic relevance.

\section{Co-infections with multiple vector-borne pathogens}

Most hyenas were infected by more than one vectorborne pathogen. The number of pathogens (Acanthocheilonema spp., B. lengau, Hepatozoon spp., Anaplasma spp., Rickettsia spp.) detected per individual and thus the extent of and species richness for 


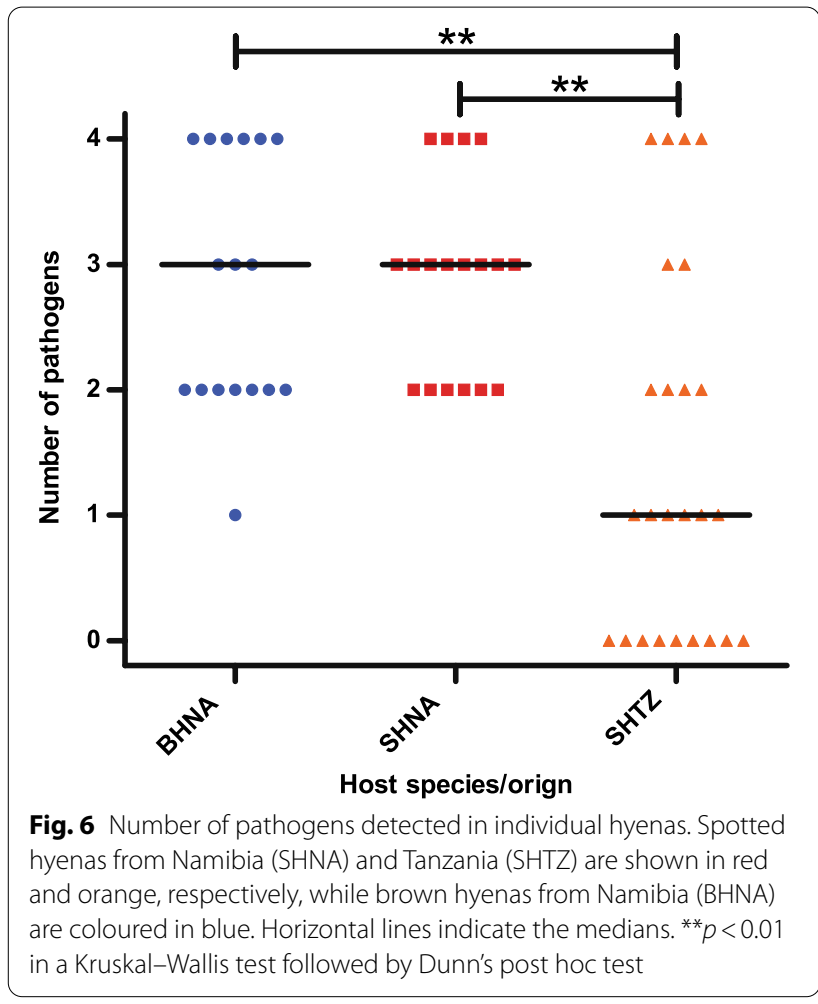

co-infections is shown for BHNA, SHNA and SHTZ in Fig. 6 . The median number of detected, simultaneously co-occurring pathogens was 3 (range 1-4) in BHNA, 3 (range 2-4) in SHNA and 1 (range 0-4) in SHTZ. The median for SHTZ was significantly lower than those for both hyena species from Namibia (both $p<0.01$, Kruskal-Wallis test followed by Dunn's post hoc test). In Namibia, brown (all from farmland) and spotted hyenas (all but one from Etosha NP) did not significantly differ in the number of co-infecting parasite types.

\section{Discussion}

Ideally, to determine the prevalence of pathogens in wildlife species or populations, the samples used should be representative in terms of age, sex and other factors such as social status, but in reality this is often difficult to achieve. For example capturing wildlife to obtain blood samples may yield samples skewed in terms of age, sex or other factors. Also, invasive sampling methods may not be permitted or are limited concerning the number of individual that can be sampled, particularly in national parks. If so, samples collected from animals shortly after their natural death (e.g. those killed by vehicles or predators) can also provide useful insights into pathogen infection, but the results from relatively small numbers of animals should be interpreted with care. Our results come from two research projects that applied different sampling and DNA isolation methods. This may have resulted in different DNA yields and quality from the samples from these projects, which may affect the comparisons of frequencies of infection between spotted hyena populations in Namibia and Tanzania.

The frequency of Anaplasmataceae was very high in SHNA (100\%) and BHNA (82.4\%) but much lower in SHTZ (32.0\%). In contrast, Burroughs et al. [42] did not detect any Anaplasmataceae in brown $(n=59)$ and spotted $(n=47)$ hyenas in Namibia and South Africa using a reverse-line blot approach. The reason for this striking difference is unclear. It might be a consequence of the different methods used, including the high number of PCR cycles used in the present study $(n=50)$, which is feasible with the Phusion DNA polymerase but not with most other polymerases. Generally, the relative frequency of detection of Anaplasmataceae in wild carnivores differed widely between various studies (range $0.0-57.7 \%$ ) as reviewed by André [13]. Remarkably, the highest value of 57.7\% was detected in South African black-backed jackals (Canis mesomelas) [70], whereas in African wild dogs also from South Africa none of 301 individuals was positive [71], with the reverse-line blot method being used in both studies. Strong differences in relative frequency of Anaplasmataceae were also observed in a recent study in caracals (Caracal caracal) from South Africa, with a prevalence of $88 \%$ in a periurban host population, and two rangeland populations showing $0 \%$ and $11 \%$ prevalence [72].

The relative frequencies of Anaplasmataceae in the Namibian BHNA and SHNA were considerably higher than in all previous studies except for the periurban caracals from South Africa, with frequencies between those of BHNA and SHNA, thus increasing the range of observed relative frequencies. The most likely explanation for the higher relative frequencies of infection in our Namibian study areas than in our study area in Tanzania are ecological differences between Southern Africa and East Africa, rather than a technical issue such as contamination, since positive samples were not clustered in particular PCR runs. In the absence of other studies from East Africa, we do not know whether the relatively low frequencies of infection in spotted hyenas from the Serengeti NP is representative of the prevalence in East African wild carnivores in general. In summary, our results and those from other studies indicate that the prevalence of Anaplasmataceae in carnivores in southern Africa can be high but also highly variable, and comparison of results produced by different methods may not be valid.

Our sequence data do not allow us to identify our Anaplasma sequences to the species level. Most sequences were equally similar to A. platys, A. phagocytophilum 
and $A$. camelii. Since the latter has so far only been found a few times and only in camelids and ruminants, it is unlikely to be this species. Anaplasma platys and A. phagocytophilum (which has a very broad host spectrum) are known to infect carnivores, but undescribed, closely related species cannot be excluded. Anaplasma bovis has been reported from racoons (Procyon lotor, family Procyonidae), coatis (Nasua nasua, family Procyonidae), racoon dogs (Nyctereutes procyonoides, family Canidae), crab-eating foxes (Cerdocyon thous, family Canidae) and a bush dog (Speothos venaticus, family Canidae) from the Carnivora suborder Caniformia and Tsushima leopard cats (Prionailurus bengalensis euptilura, family Felidae) and ocelots (Leopardus pardalis, family Felidae) from the suborder Feliformia [13]. Thus, A. bovis is frequently observed in carnivores, despite its name suggesting it is a parasite of cattle or more generally of ruminants, and finding $A$. bovis-like genotypes in spotted hyenas in Tanzania is therefore not unexpected.

The only Rickettsia species found in this study was $R$. raoultii. This species has been associated predominantly with Dermacentor spp. ticks in Eurasia, causing tickborne lymphadenopathy/Dermacentor-borne necrosis erythema lymphadenopathy/scalp eschar neck lymphadenopathy (TIBOLA/DEBONEL/SENLAT) in humans $[73,74]$. In D. reticulatus, prevalence exceeding $70 \%$ was observed in some locations [69], whereas direct detection of $R$. raoultii in non-human hosts has been rare. Liesner et al. [75] found seven out of 1023 (0.7\%) domestic dog blood samples and none of 195 red fox (Vulpes vulpes) spleen samples from Brandenburg (Germany) to be positive, despite $D$. reticulatus occurring in the area at high abundance and high prevalence of $R$. raoultii in the local tick population $[58,69,76]$. In wildlife, $R$. raoultii has been detected in one Mongolian gazelle (Procapra gutturosa) [77] and one marbled polecat (Vormela peregusna) [78] in China, two bank voles (Myodes glareolus) [79] and a common vole (Microtus arvalis) [80] in Germany and a wild boar (Sus scrofa) in Italy [81]. As far as we know, finding $R$. raoultii in brown and spotted hyenas is the first reported presence of this spotted fever Rickettsia species in sub-Saharan Africa. The vector tick responsible for transmission in Africa remains unclear. The only member of the genus Dermacentor known to occur in southern Africa is Dermacentor rhinocerinus. Adults of this parasite feed quite specifically on black (Diceros bicornis) and southern white (Ceratotherium simum) rhinoceros in southern Africa [82]; little is known about the hosts of the larvae and nymphs of $D$. rhinocerinus. In one study, larvae and nymphs were observed to feed on rodents [83]. Given this lack of information, transmission by immature $D$. rhinocerinus stages to hyenas cannot currently be excluded.
Hepatozoon spp. have been known to infect spotted hyenas in South Africa [44] and Tanzania [45]. East et al. [45] identified hepatozoonosis as an important cause of death in juvenile hyenas. In Zambia, both $H$. felis-like and $H$. canis-like sequences were amplified from spotted hyena samples [41]. As far as we know, the present study is the first to report and characterise Hepatozoon spp. from brown hyenas. Our phylogenetic analysis revealed that Hepatozoon spp. from both hyena species are not identical to the typical Hepatozoon genotype $(H$. felis s.s.) found in domestic cats. Most Hepatozoon species included in the analysis as outgroups, such as $H$. canis, Hepatozoon ursi or Hepatozoon martis, were all placed between the homogeneous $H$. felis s.s. group and the group containing sequences obtained from hyenas in this study. The latter are more diverse than the $H$. felis s.s. group and are located between sequences assigned to $H$. felis in GenBank ${ }^{\circledR}$ obtained from domestic cats and wild felids. This suggests that assignment of the hyena parasites to the taxon $H$. felis should be considered with care. Analyses with full-length 18S rRNA and additional markers will be required to resolve the phylogenetic position with sufficient accuracy.

The primer pair we used to detect piroplasms detected $B$. lengau and B. vogeli in the samples. Babesia lengau, a close relative of $B$. conradae and $B$. duncani, is not a "classical" Babesia (Babesia sensu stricto) species like $B$. canis or Babesia bovis. Babesia lengau is very distantly related to the "classical" Babesia group and belongs to the so-called Western group of piroplasms [84], while $B$. vogeli belongs to the group of Babesia s.s. In addition to the expected Babesia species, $H$. felis-like and Sarcocystis spp. parasites were found. This primer pair is very widely used, since it is able to amplify all groups of piroplasms. However, it is also recognised to lack sufficient specificity for Piroplasmida due to some cross-reactivity with Coccidia [85] and Hepatozoon spp. Thus, methods such as sequencing or reverse-line blot must be applied to positive samples to confirm the presence of piroplasms and identify the species.

Furthermore, the primers for piroplasms did not exactly match the target sequences in B. lengau-like GenBank entries, suggesting not only limited specificity but also limited sensitivity for this particular group. To improve both specificity and sensitivity, a $B$. lengau/B. conradae group PCR was developed. Under the optimised PCR conditions, no cross-reactivity was observed. Sequence identity of the new primers targeting the $B$. lengau/B. conradae group to sequences from tissue-cystforming coccidia such as Sarcocystis or Toxoplasma was very low (maximum of 14 consecutive identical bases for the 25 bp specific forward primer and no perfect identities at the $3^{\prime}$ end of the primer), and an amplification 
of these parasites was considered to be unlikely at an annealing temperature of $95{ }^{\circ} \mathrm{C}$. Sequence analyses of initially amplified samples did not show any hint that the optimised PCR would also pick up tissue-cyst-forming coccidians; all analysed sequences were of the $B$. lengau type. Using this PCR, the frequency of $B$. lengau was significantly lower in SHTZ than in both hyena species from Namibia, whereas a comparison between the two hyena species in Namibia revealed no significant difference. These results are not consistent with the expectation that anthropogenic factors on farmland in Namibia result in higher infection of brown hyenas than spotted hyenas in Etosha NP, but are consistent with the prediction of lower infection in spotted hyenas in the Serengeti NP than in both Namibian study areas. Furthermore, the comparatively small difference between hyenas inhabiting farmland and Etosha NP may indicate that relatively similar factors affect both areas (such as those associated with artificial sources of water) and perhaps a lower prevalence of infected ticks in farmland, where some farmers take measures to control ticks, other than large-scale burning of swards as in the Serengeti NP.

Burroughs et al. [42] sequenced nearly full-length $18 \mathrm{~S}$ rRNA genes of B. lengau-like piroplasms from brown and spotted hyenas in Namibia and South Africa and identified four genotype groups. As their sequences have not been published and were not accessible, they could not be included in the analysis. Babesia lengau-like piroplasms were associated with severe clinical symptoms in two domestic cats in South Africa [86] and an outbreak of piroplasmosis in two domestic sheep flocks in Greece [47]. Clinical signs in both host species included severe haemolysis and anaemia. The sheep also showed haemoglobinuria, and one domestic cat showed considerable histopathological changes in the brain. Findings of $B$. lengau-like piroplasms in six spotted hyenas and a single lion (Panthera leo) from Zambia [41] suggest that these parasites have a large geographical distribution in southern Africa and a host range that might include many Feliformia. Very similar sequences were obtained from a golden jackal (Canis aureus) and four red foxes from Israel [87], labelled "Near East carnivore Babesia" in Fig. 2. With the exception of the Greek outbreak in sheep, all hosts belonged to the order Carnivora. Since species of the families Felidae, Hyaenidae, Herpestidae and Canidae were infected, investigating carnivore species of other families, particularly in Africa, might help to provide a more complete picture of the host range.

With the pan-piroplasm PCR, we identified a single $B$. vogeli-like sequence in a SHTZ. Although $B$. vogeli is widely considered to be a canine parasite, it was repeatedly demonstrated to occur in domestic cats from Brazil, China, Portugal, Qatar and Thailand [13, 88-92]. In
Spain, the parasite was also detected in stone martens (Martes foina) using real-time PCR and applying a $B$. vogeli-specific probe [93]. Such data suggest that $B$. vogeli and closely related genotypes have a wide host range and can also be expected to be present in other wild carnivore species.

With the pan-piroplasm PCR we also identified a Sarcocystis spp. sequence in one SHTZ. Carnivores are often definitive hosts of Sarcocystis spp. but a few species also use carnivores as intermediate hosts, such as Sarcocystis caninum and Sarcocystis svanai in domestic dogs and Sarcocystis arctica in arctic foxes (Vulpes lagopus) and red foxes [94-98]. Since the life cycle includes stages that infect mononuclear cells, finding Sarcocystis spp. in blood samples during acute infections is not surprising and has been previously reported [75]. As a method to estimate prevalence, PCR analysis of blood samples is unsuitable, since the prevalence in muscle tissue of chronically infected animals will be far higher than the prevalence in blood. The phylogenetic analysis placed this Sarcocystis sp. ex Crocuta crocuta in a sister position to a Sarcocystis from a white-tailed mongoose from South Africa. This suggests that at least closely related Sarcocystis species might use several Carnivora in Southern Africa as intermediate host. To identify the parasite species and their intermediate and definitive host specificity, systematic screening of muscle samples would be required.

The genetic variability of the Acanthocheilonema sequences obtained from hyenas was very high. These apparently represent several previously unrecognised species. In order to resolve them taxonomically, combined morphological and molecular analyses of adult worms will be required. For $D$. repens, multiple cryptic species were identified which come from different geographic locations and may also have different host ranges, suggesting that species diversity of filarioid parasites is considerably underestimated [99-101]. For strongyle nematodes, the combination of morphological and molecular data revealed synonyms $[102,103]$ as well as cryptic species [104, 105].

This also suggests that previous reports of $A$. dracunculoides in spotted hyenas and domestic dogs in Kenya [48] should be treated with caution. It might be that the microfilaria of two different species infecting hyenas and domestic dogs were morphologically undistinguishable from $A$. dracunculoides and that only the domestic dogs were infected with $A$. dracunculoides. Alternatively, spotted hyenas and domestic dogs in Kenya might be infected by an Acanthocheilonema species similar to Acanthocheilonema sp. ex Hyaenidae. To discriminate between these possibilities, systematic blood sampling and PCR/sequencing analyses of blood from hyena and domestic carnivores living in overlapping habitats would 
be required. This should also include efforts to identify potential vector species. As mentioned above, the spectrum of vectors for filarioids is broad. In the genus Acanthocheilonema this variation in vectors is particularly high. While the rodent parasite Acanthocheilonema viteae uses the soft tick Ornithodorus tartakovskyi [106], A. dracunculoides infecting domestic dogs is transmitted by the brown dog tick Rhipicephalus sanguineus $[107,108]$ and the louse fly $H$. longipennis [38]. The other Acanthocheilonema species commonly found in domestic dogs, A. reconditum, uses various fleas (including Ctenocephalides spp. and Pulex spp.) as well as lice (Heterodoxus spiniger, Linognathus setosus) as vectors [109]. The Acanthocheilonema species labelled $A$. reconditum-like in Figure 5 from domestic dogs in India was also demonstrated to develop to infective third larvae in H. longipennis [40]. The seal heartworm $A$. spirocauda is transmitted by the seal louse Echinophthirius horridus [110, 111]. It is interesting that adults of the latter species are not located in sites where they cause little damage, such as the peritoneal cavity (A. dracunculoides) or the subcutis (A. reconditum), but in the heart, where they can potentially cause anorexia and fatigue that may lead to more severe heart and lung complications and sometimes death [112]. Without any pathological evidence obtained in necropsies, it cannot be predicted whether the Acanthocheilonema species found in hyenas causes only low to moderate pathologies as those in domestic dogs, or severe clinical symptoms as $A$. spirocauda in seals.

Our finding that Anaplasmataceae and B. lengau-like piroplasms were present significantly more often in hyenas in Namibia than in Tanzania may indicate underlying regional differences between southern and eastern Africa, in terms of tick species diversity and climatic factors. Human activities are also likely to play a role through their effect on vector abundance and distribution, the density of hosts for larval stages and density of other competent host species that share pathogens with brown and spotted hyenas [113]. As expected, higher frequencies of some pathogens also resulted in higher frequencies of co-infection with multiple pathogens. Coinfections with multiple pathogens is generally the rule and not an exception in wildlife [114], but currently little is known of the effect concurrent infection with multiple pathogens has on wildlife at the individual or population level. Potential interactions include competition for resources such as host cells or nutrients, interaction via immune responses and production of chemical compounds. Pathogens may facilitate each other mutually, or only in a single direction, by suppressing the immune system, or might antagonise each other in cases where they compete for the same host cell or nutrients provided by the host. Indirect immunological interactions might lead to synergistic or antagonistic interactions between pathogens [114].

Considering that most emerging diseases are zoonotic and that most of these originate from wildlife, studies looking more systematically into co-infections in wildlife are urgently needed. The application of metagenomics methods in future studies on co-infections in wildlife should produce new insights [114], as was recently demonstrated by a study using faecal samples from SHTZ [115]. Additionally, as gastrointestinal helminth parasites can strongly interact with concurrent systemic malaria parasites located in very different organ systems [116, 117], analyses of multiple samples such as blood, faeces and urine from the same animal would improve knowledge on how co-infecting parasites interact and how their joint presence and activities affect their hosts.

\section{Conclusions}

This study presents the relative frequencies of infections of several vector-borne pathogens in two hyena species from two African regions and three study sites with different ecological conditions. In general, the brown and spotted hyenas in Namibia had higher infection frequencies and higher species richness in terms of co-infections than the spotted hyenas in Tanzania. These differences are more likely related to differences in ecological conditions in geographic regions and study areas and the variable degree of vector-related human activities than to differences between the two species in terms of their immunological defences against infection. The genetic diversity of several parasite species was very high, suggesting that for several Acanthocheilonema spp., Babesia spp. and presumably also Hepatozoon spp. new species were detected that should be fully described with morphological details and deposition of type material in the future. Species not identical to well-described parasites of domestic dogs and domestic cats such as A. dracunculoides, $B$. vogeli and $H$. canis may have different life cycles and arthropod vectors that require parasitological and molecular investigation. The large number of Babesia species (including $B$. lengau-like genotypes) recently described from domestic cats [118] suggests that many of these pathogens may infect domestic cats and dogs and cause severe disease but have been overlooked so far [10, 86]. Currently, little is known regarding the pathology and outcome of infection caused by these pathogens in brown and spotted hyenas, and the same is true for coinfections that were common, particularly in Namibia. Further research is needed to assess the effect of these vector-borne pathogens on the health status and survival of brown and spotted hyenas. 


\section{Abbreviations}

BHNA: Brown hyena Namibia; SHNA: Spotted hyena Namibia; SHTZ: Spotted hyena Tanzania; NP: National park; gltA: Citrate synthase; rRNA: Ribosomal RNA; ITS1: Internal transcribed spacer 1; ITS2: Internal transcribed spacer 2.

\section{Supplementary Information}

The online version contains supplementary material available at https://doi. org/10.1186/s13071-021-04835-x.

Additional file 1: Table S1. Raw data on all hyena specimens. Data include an arbitrary ID, the host species, an assigned group (BHNA, brown hyena Namibia, SHNA, spotted hyena Namibia; SHTZ, spotted hyena Tanzania), the year of collection, age (subadult, adult), the sample tissue, the area where the individual was found (farmland, Etosha NP, Serengeti $N P)$, the country and region within the country. Results of PCRs for different pathogen groups are indicated as 0 and 1 for positive and negative, respectively. Sequencing results columns show the best taxonomic assignment to the sample based on sequencing data. Finally, the number of pathogen taxa detected in each specimen are indicated.

Additional file 2: Table S2. Primer sequences and PCR conditions.

\section{Acknowledgements}

We are grateful to the Ministry of Environment and Tourism in Namibia and the Tanzania Commission for Science and Technology (COSTECH) for permission to conduct this study and to the Tanzania Wildlife Research Institute, Tanzanian National Park Authority and COSTECH for their support of our research. We thank the Namibian farmers for their collaboration and the field assistants for help. In Tanzania we thank R. Fyumagwa, M. Jago, M. RoelkeParke, J. Shamananche, H. Wiik for veterinary assistance, Annie Francis, Stephan Karl, Sonja Metzger, and Dagmar Thierer and all field assistants for their help. We acknowledge support by the Open Access Publication Initiative of the Freie Universität Berlin. We thank two anonymous reviewers for their helpful comments.

\section{Authors' contributions}

JK, GAC, HH, LMdC, GVSH, MLE and BW designed and supervised the study. SKH, JM, OHKA, NAB, BW, HH and MLE collected the samples. SR, MCC, MS and SC performed the molecular analyses. JK performed the statistical and phylogenetic analyses. JK and SR wrote the first draft. BW, GÁC, HH and MLE revised the first draft. All authors edited the draft versions. All authors read and approved the final manuscript.

\section{Funding}

Open Access funding enabled and organized by Projekt DEAL. This study was funded by the Deutsche Forschungsgemeinschaft (German Research Foundation, DFG) through the Research Training Group GRK 2046 "Parasite Infections: From experimental models to natural systems" (project number 251133687/ GRP2046), by the Messerli Foundation, Switzerland, and by the Leibniz Institute for Zoo and Wildlife Research, Germany. MCC's and SC's traineeships at the Institute for Parasitology and Tropical Veterinary Medicine, Freie Universität Berlin, Germany were financially supported by the Erasmus + program (contract number 022363 218/SMT/2016 and 29/08 SC/SMT/2018, respectively) of the European Union. Part of the laboratory costs were contributed by internal funds from Freie Universität Berlin.

\section{Availability of data and materials}

All data generated or analysed during this study are included in this article and its additional files. Sequence data were deposited in the GenBank database under the accession numbers listed in Additional file 1: Table S1.

\section{Declarations}

Ethics approval and consent to participate

All handling of animals was performed by or under direct supervision of the wild life veterinarian responsible for the sampling areas, ensuring compliance with animal welfare regulations. All experimental procedures, including animal immobilisation and sample collection, were approved by the Internal Ethics
Committee of the Leibniz Institute for Zoo and Wildlife Research (Leibniz-IZW, permit number 2002-04-01) and authorised by the Ministry of Environment and Tourism of Namibia (permit numbers 1689/2012, 1813/2013 and 1914/2014) and by the Tanzania Commission for Science and Technology (permit number 2019-146-NA-90-130). All experiments were carried out in compliance with the approved guidelines of the Leibniz-IZW and the laws of Germany, Tanzania and Namibia.

\section{Consent for publication}

Not applicable.

\section{Competing interests}

The authors declare that they have no competing interests.

\section{Author details}

${ }^{1}$ Institute for Parasitology and Tropical Veterinary Medicine, Freie Universität Berlin, Berlin, Germany. ${ }^{2}$ Department of Wild life Diseases, Leibniz Institute for Zoo and Wildlife Research, Berlin, Germany. ${ }^{3}$ Department of Evolutionary Ecology, Leibniz Institute for Zoo and Wildlife Research, Berlin, Germany. ${ }^{4}$ Centro de Investigação Interdisciplinar Em Sanidade Animal, Faculdade de Medicina Veterinária, Universidade de Lisboa, Lisbon, Portugal. ${ }^{5}$ Leibniz Institute for Zoo and Wildlife Research, Berlin, Germany. ${ }^{6}$ Department of Veterinary Medicine, Freie Universität Berlin, Berlin, Germany. ${ }^{7}$ Department of Biology, Freie Universität Berlin, Berlin, Germany. ${ }^{8}$ School of Veterinary Medicine, University of Namibia, Windhoek, Namibia. ${ }^{9}$ School of Life Sciences, University of KwaZulu-Natal, Durban, South Africa. ${ }^{10}$ Department of Veterinary Medicine, University Federico II of Naples, Naples, Italy. ${ }^{11}$ Department of Ecological Dynamics, Leibniz Institute for Zoo and Wildlife Research, Berlin, Germany.

Received: 3 April 2021 Accepted: 9 June 2021

Published online: 16 June 2021

\section{References}

1. Frank LG, Holekamp KE, Smale L. Dominance, demography, and reproductive success of female spotted hyenas. In: Sinclair ARE, Areese P, editors. Serengeti II - Dyn conserv manag an ecosyst. Chicago: University of Chicago Press; 1995. p. 364-84.

2. Matijatko V, Torti M, Schetters TP. Canine babesiosis in Europe: how many diseases? Trends Parasitol. 2012;28:99-105.

3. Solano-Gallego L, Sainz Á, Roura X, Estrada-Peña A, Miró G. A review of canine babesiosis: the European perspective. Parasit Vectors. 2016;9:336.

4. Dantas-Torres F, Otranto D. Dirofilariosis in the Americas: a more virulent Dirofilaria immitis? Parasit Vectors. 2013;6:288. https://doi.org/10.1186/ 1756-3305-6-288

5. Hoch H, Strickland K. Canine and feline dirofilariasis: life cycle, pathophysiology, and diagnosis. Compend Contin Educ Vet. 2008;30:133-40 (quiz 141).

6. Day MJ. One health: the importance of companion animal vectorborne diseases. Parasit Vectors. 2011;4:49.

7. Otranto D. Arthropod-borne pathogens of dogs and cats: from pathways and times of transmission to disease control. Vet Parasitol. 2018:251:68-77.

8. Otranto D, Dantas-Torres F, Breitschwerdt EB. Managing canine vector-borne diseases of zoonotic concern: part one. Trends Parasitol. 2009;25:157-63.

9. Otranto D, Dantas-Torres F, Breitschwerdt EB. Managing canine vector-borne diseases of zoonotic concern: part two. Trends Parasitol. 2009;25:228-35.

10. Penzhorn BL. Why is Southern African canine babesiosis so virulent? An evolutionary perspective. Parasit Vectors. 2011;4:51.

11. Baneth G, Thamsborg SM, Otranto D, Guillot J, Blaga R, Deplazes P, et al. Major parasitic zoonoses associated with dogs and cats in Europe. J Comp Pathol. 2016;155:S54-74.

12. Alvarado-Rybak M, Solano-Gallego L, Millán J. A review of piroplasmid infections in wild carnivores worldwide: importance for domestic animal health and wildlife conservation. Parasit Vectors. 2016;9:538.

13. André MR. Diversity of anaplasma and Ehrlichia/Neoehrlichia agents in terrestrial wild carnivores worldwide: implications for human and 
domestic animal health and wildlife conservation. Front Vet Sci. 2018. https://doi.org/10.3389/fvets.2018.00293/full.

14. Otranto D, Deplazes P. Zoonotic nematodes of wild carnivores. Int J Parasitol Parasites Wildl. 2019;9:370-83.

15. Espinaze MPA, Hellard E, Horak IG, Cumming GS. Domestic mammals facilitate tick-borne pathogen transmission networks in South African wildlife. Biol Conserv. 2018;221:228-36.

16. Morand S, Krasnov BR, editors. The biogeography of host-parasite interactions. New York: Oxford University Press: 2010.

17. Hofer H, Mills MGL. Population size, threats and conservation status of hyaenas. In: Hofer H, Mills MGL, editors. Hyaenas Status Surv Conserv Action Plan. Gland, Switzerland and Cambridge, UK.: IUCN/SSC Hyaena Specialist Group. IUCN; 1998. p. 64-79.

18. Mills MGL. Kalahari hyaenas: the comparative behavioural ecology of two species. Hyman U, editor. London: 1990.

19. Stein AB, Fuller TK, Marker LL. Brown hyaena feeding ecology on Namibian Farmlands. South African J Wildl Res. 2013;43:27-32. https://doi.org/10.3957/056.043.0115.

20. Lindsey PA, Havemann CP, Lines R, Palazy L, Price AE, Retief TA, et al. Determinants of persistence and tolerance of carnivores on Namibian ranches: Implications for conservation on Southern African private lands. PLOS ONE. 2013;8:e52458. https://doi.org/10.1371/journal. pone.0052458.

21. Kent $\mathrm{VT}$, Hill RA. The importance of farmland for the conservation of the brown hyaena Parahyaena brunnea. Oryx. 2013;47:431-40.

22. Mills MGL. Brown hyaena Hyaena (Parahyaena) brunnea (Thunberg, 1820). In: Mills MGL, Hofer H, editors. Hyaenas Status Surv Conserv Action Plan. Gland, Switzerland and Cambridge, UK.: IUCN/SSC Hyaena Specialist Group. IUCN; 1998. p. 26-9.

23. Trinkel M, Fleischmann PH, Kastberger G. Comparison of land-use strategies of spotted hyenas (Crocuta crocuta, Erxleben) in different ecosystems. Afr J Ecol. 2006;44:537-9. https://doi.org/10.1111/j.13652028.2006.00658.x.

24. Hofer H, East ML. Population dynamics, population size and the commuting system of spotted hyaenas in the Serengeti. In: Sinclair A, Arcese P, editors. Serengeti II Dyn Manag Conserv an Ecosyst. Chicago: University of Chicago Press; 1995. p. 332-63.

25. Hofer $\mathrm{H}$, East ML. Behavioral processes and costs of co-existence in female spotted hyenas: a life history perspective. Evol Ecol. 2003;17:315-31. https://doi.org/10.1023/A:1027352517231.

26. Olarte-Castillo XA, Hofer H, Goller KV, Martella V, MoehIman PD, East $M L$. Divergent sapovirus strains and infection prevalence in wild carnivores in the Serengeti Ecosystem: a long-term study. PLoS ONE. 2016;11:e0163548.

27. Ferreira SCM, Hofer H, Madeira de Carvalho L, East ML. Parasite infections in a social carnivore: Evidence of their fitness consequences and factors modulating infection load. Ecol Evol. 2019;9:8783-99.

28. Nikolin VM, Olarte-Castillo XA, Osterrieder N, Hofer H, Dubovi E, Mazzoni CJ, et al. Canine distemper virus in the Serengeti ecosystem: molecular adaptation to different carnivore species. Mol Ecol. 2017:26:2111-30

29. East ML, Kurze C, Wilhelm K, Benhaiem S, Hofer H. Factors influencing Dipylidium sp. infection in a free-ranging social carnivore, the spotted hyaena (Crocuta crocuta). Int J Parasitol Parasites Wildl. 2013:2:257-65

30. East ML, Hofer H, Cox JH, Wulle U, Wiik H, Pitra C. Regular exposure to rabies virus and lack of symptomatic disease in Serengeti spotted hyenas. Proc Natl Acad Sci USA. 2001;98:15026-31.

31. Hofer H, East ML. The commuting system of Serengeti spotted hyaenas: how a predator copes with migratory prey. III. Attendance and maternal care. Anim Behav. 1993;46:575-89.

32. Trinkel M, Fleischmann PH, Steindorfer AF, Kastberger G. Spotted hyenas (Crocuta crocuta) follow migratory prey Seasonal expansion of a clan territory in Etosha, Namibia. J Zool. 2004;264:125-33. https://doi. org/10.1017/S0952836904005588.

33. Sinclair ARE. Serengeti past and present. In: Sinclair ARE, Arcese P, editors. Serengeti II Dyn Manag Conserv an Ecosyst. Chicago: University of Chicago Press; 1995. p. 3-30

34. Redfern JV, Grant R, Biggs H, Getz WM. Surface-water constraints on herbivore foraging in the Kruger National Park,South Africa. Ecology. 2003;84:2092-107. https://doi.org/10.1890/01-0625.
35. Goodenough AE, Harrell AN, Keating RL, Rolfe RN, Stubbs H, MacTavish $L$, et al. Managing grassland for wild life: the effects of rotational burning on tick presence and abundance in African savannah habitat. Wildl Biol. 2017. https://doi.org/10.2981/wlb.00318.

36. de la Fuente J. Overview: Ticks as vectors of pathogens that cause disease in humans and animals. Front Biosci. 2008;13:6938.

37. Lefoulon E, Bain O, Bourret J, Junker K, Guerrero R, Cañizales I, et al. Shaking the tree: multi-locus sequence typing usurps current Onchocercid (Filarial Nematode) phylogeny. PLoS Negl Trop Dis. 2015;9:e0004233. https://doi.org/10.1371/journal.pntd.0004233.

38. Nelson GS. Dipetalonema dracunculoides (Cobbold, 1870), from the dog in Kenya: with a note on its development in the louse-fly Hippobosca longipennis. J Helminthol. 1963;37:235-40.

39. Nelson GS. Dipetalonema reconditum (Grassi, 1889) from the Dog with a Note on its Development in the Flea, Ctenocephalides felis and the Louse Heterodoxus spiniger. J Helminthol. 1962;36:297-308.

40. Rani PAMA, Coleman GT, Irwin PJ, Traub RJ. Hippobosca longipennis - a potential intermediate host of a species of Acanthocheilonema in dogs in northern India. Parasit Vectors. 2011;4:143. https://doi.org/10.1186/ 1756-3305-4-143.

41. Williams BM, Berentsen A, Shock BC, Teixiera M, Dunbar MR, Becker MS, et al. Prevalence and diversity of Babesia, Hepatozoon, Ehrlichia, and Bartonella in wild and domestic carnivores from Zambia, Africa. Parasitol Res. 2014;113:911-8. https://doi.org/10.1007/s00436-013-3722-7.

42. Burroughs REJ, Penzhorn BL, Wiesel I, Barker N, Vorster I, Oosthuizen MC. Piroplasms in brown hyaenas (Parahyaena brunnea) and spotted hyaenas (Crocuta crocuta) in Namibia and South Africa are closely related to Babesia lengau. Parasitol Res. 2017;116:685-92. https://doi.org/10.1007/ s00436-016-5334-5.

43. Heisch RB, Grainger WE, Harvey AEC, Lister G. Feral aspects of Rickettsial infections in Kenya. Trans R Soc Trop Med Hyg. 1962;56:272-82. https:// doi.org/10.1016/0035-9203(62)90048-2.

44. McCully RM, Basson PA, Bigalke RD, de Vos V, Young E. Observations on naturally acquired hepatozoonosis of wild carnivores and dogs in the Republic of South Africa. Onderstepoort J Vet Res. 1975;42:117-33.

45. East ML, Wibbelt G, Lieckfeldt D, Ludwig A, Goller K, Wilhelm K, et al. A Hepatozoon species genetically distinct from $\mathrm{H}$. canis infecting spotted hyenas in the serengeti ecosystem, Tanzania. J Wildl Dis. 2008;44:45-52. https://doi.org/10.7589/0090-3558-44.1.45.

46. Bosman A-M, Oosthuizen MC, Peirce MA, Venter EH, Penzhorn BL. Babesia lengau sp. nov., a novel Babesia species in cheetah (Acinonyx jubatus, Schreber, 1775) populations in South Africa. J Clin Microbiol. 2010;48:2703-8

47. Giadinis ND, Chochlakis D, Kritsepi-Konstantinou M, Makridaki E, Tselentis Y, Kostopoulou D, et al. Haemolytic disease in sheep attributed to a Babesia lengau -like organism. Vet Rec. 2012;170(155):2-155. https://doi. org/10.1136/vr.100394.

48. Lightner LK, Reardon MJ. Dipetalonema dracunculoides in Dogs and Spotted Hyena (Crocuta crocuta) in the Turkana District of Kenya. Proc Helminthol Soc Wash. 1983;50:333-5.

49. Schwan EV, Schroter FG. First record of Acanthocheilonema dracunculoides from domestic dogs in Namibia. J S Afr Vet Assoc. 2006;77:220-1.

50. Seltmann A, Schares G, Aschenborn OHK, Heinrich SK, Thalwitzer S, Wachter B, et al. Species-specific differences in Toxoplasma gondii, Neospora caninum and Besnoitia besnoiti seroprevalence in Namibian wildlife. Parasit Vectors. 2020;13:7. https://doi.org/10.1186/ s13071-019-3871-3.

51. Thalwitzer S, Wachter B, Robert N, Wibbelt G, Müller T, Lonzer J, et al. Seroprevalences to viral pathogens in free-ranging and captive cheetahs (Acinonyx jubatus) on Namibian Farmland. Clin Vaccine Immunol. 2010;17:232-8.

52. Wassermann M, Aschenborn O, Aschenborn J, Mackenstedt U, Romig T. A sylvatic lifecycle of Echinococcus equinus in the Etosha National Park, Namibia. Int J Parasitol Parasites Wildl. 2015:4:97-103.

53. Casiraghi M, Bain O, Guerrero R, Martin C, Pocacqua V, Gardner SL, et al. Mapping the presence of Wolbachia pipientis on the phylogeny of filarial nematodes: evidence for symbiont loss during evolution. Int J Parasitol. 2004:34:191.

54. Inokuma H, Okuda M, Ohno K, Shimoda K, Onishi T. Analysis of the $18 \mathrm{~S}$ rRNA gene sequence of a Hepatozoon detected in two Japanese dogs. Vet Parasitol. 2002;106:265-71. 
55. Matjila PT, Penzhorn BL, Bekker CPJ, Nijhof AM, Jongejan F. Confirmation of occurrence of Babesia canis vogeli in domestic dogs in South Africa. Vet Parasitol. 2004;122:119-25.

56. Rishniw M, Barr SC, Simpson KW, Frongillo MF, Franz M, Dominguez Alpizar JL. Discrimination between six species of canine microfilariae by a single polymerase chain reaction. Vet Parasitol. 2006;135:303-14.

57. Roux V, Rydkina E, Eremeeva M, Raoult D. Citrate synthase gene comparison, a new tool for phylogenetic analysis, and its application for the rickettsiae. Int J Syst Bacteriol. 1997;47:252-61.

58. Schreiber C, Krücken J, Beck S, Maaz D, Pachnicke S, Krieger K, et al. Pathogens in ticks collected from dogs in Berlin/Brandenburg, Germany. Parasit Vectors. 2014;7:535.

59. Tabar M-D, Altet L, Francino O, Sánchez A, Ferrer L, Roura X. Vectorborne infections in cats: molecular study in Barcelona area (Spain). Vet Parasitol. 2008;151:332-6.

60. Helm CS, von Samson-Himmelstjerna G, Liesner JM, Kohn B, Müller E, Schaper R, et al. Identical 18 S rRNA haplotypes of Hepatozoon canis in dogs and foxes in Brandenburg, Germany. Ticks Tick Borne Dis. 2020;11:101520.

61. Altschul SF, Gish W, Miller W, Myers EW, Lipman DJ. Basic local alignment search tool. J Mol Biol. 1990;215:403-10.

62. Katoh K, Standley DM. MAFFT multiple Sequence Alignment Software Version 7: improvements in performance and usability. Mol Biol Evol. 2013;30:772-80. https://doi.org/10.1093/molbev/mst010.

63. Katoh K, Rozewicki J, Yamada KD. MAFFT online service: multiple sequence alignment, interactive sequence choice and visualization. Brief Bioinform. 2019:20:1160-6.

64. Kalyaanamoorthy S, Minh BQ, Wong TKF, von Haeseler A, Jermiin LS. ModelFinder: fast model selection for accurate phylogenetic estimates. Nat Methods. 2017;14:587-9.

65. Nguyen L-T, Schmidt HA, von Haeseler A, Minh BQ. IQ-TREE: a fast and effective stochastic algorithm for estimating maximum-likelihood phylogenies. Mol Biol Evol. 2015;32:268-74. https://doi.org/10.1093/ molbev/msu300.

66. Trifinopoulos J, Nguyen L-T, von Haeseler A, Minh BQ. W-IQ-TREE: a fast online phylogenetic tool for maximum likelihood analysis. Nucleic Acids Res. 2016;44:W232-5. https://doi.org/10.1093/nar/ gkw256.

67. Hoang DT, Chernomor O, von Haeseler A, Minh BQ, Vinh LS. UFBoot2: improving the ultrafast bootstrap approximation. Mol Biol Evol. 2018;35:518-22.

68. Guindon S, Dufayard J-F, Lefort V, Anisimova M, Hordijk W, Gascuel O. New algorithms and methods to estimate maximum-likelihood phylogenies: assessing the performance of PhyML 3.0. Syst Biol. 2010;59:307-21.

69. Kohn M, Krücken J, McKay-Demeler J, Pachnicke S, Krieger K, von Samson-Himmelstjerna G. Dermacentor reticulatus in Berlin/ Brandenburg (Germany): activity patterns and associated pathogens. Ticks Tick Borne Dis. 2019;10:191-206.

70. Penzhorn BL, Netherlands EC, Cook CA, Smit NJ, Vorster I, HarrisonWhite RF, et al. Occurrence of Hepatozoon canis (Adeleorina: Hepatozoidae) and Anaplasma spp. (Rickettsiales: Anaplasmataceae) in black-backed jackals (Canis mesomelas) in South Africa. Parasit Vectors. 2018;11:158. https://doi.org/10.1186/s13071-018-2714-y.

71. Matjila PT, Leisewitz AL, Jongejan F, Bertschinger HJ, Penzhorn BL. Molecular detection of Babesia rossi and Hepatozoon sp. in African wild dogs (Lycaon pictus) in South Africa. Vet Parasitol. 2008;157:123-7.

72. Viljoen S, O'Riain MJ, Penzhorn BL, Drouilly M, Serieys LEK, Cristescu B, et al. Molecular detection of tick-borne pathogens in caracals (Caracal caracal) living in human-modified landscapes of South Africa. Parasit Vectors. 2020;13:220. https://doi.org/10.1186/s13071-020-04075-5.

73. Portillo A, Santibáñez S, García-Álvarez L, Palomar AM, Oteo JA. Rickettsioses in Europe. Microbes Infect. 2015;17:834-8.

74. Silva-Pinto A, de Santos ML, Sarmento A. Tick-borne lymphadenopathy, an emerging disease. Ticks Tick Borne Dis. 2014;5:656-9.

75. Liesner JM, Krücken J, Schaper R, Pachnicke S, Kohn B, Müller E, et al. Vector-borne pathogens in dogs and red foxes from the federal state of Brandenburg Germany. Vet Parasitol. 2016;224:44-51.
76. Beck S, Schreiber C, Schein E, Krücken J, Baldermann C, Pachnicke S, et al. Tick infestation and prophylaxis of dogs in northeastern Germany: a prospective study. Ticks Tick Borne Dis. 2014;5:336-42.

77. Li Y, Chen Z, Liu Z, Liu J, Yang J, Li Q, et al. First report of Theileria and Anaplasma in the Mongolian gazelle, Procapra gutturosa. Parasit Vectors. 2014;7:614. https://doi.org/10.1186/s13071-014-0614-3.

78. Liu X, Yang M, Liu G, Zhao S, Yuan W, Xiao R, et al. Molecular evidence of Rickettsia raoultii, "Candidatus Rickettsia barbariae" and a novel Babesia genotype in marbled polecats (Vormela peregusna) at the ChinaKazakhstan border. Parasit Vectors. 2018;11:450. https://doi.org/10. 1186/s13071-018-3033-z.

79. Obiegala A, Oltersdorf C, Silaghi C, Kiefer D, Kiefer M, Woll D, et al. Rickettsia spp. in small mammals and their parasitizing ectoparasites from Saxony, Germany. Vet Parasitol Reg Stud Rep. 2016;5:19-24.

80. Fischer S, Spierling NG, Heuser E, Kling C, Schmidt S, Rosenfeld UM, et al. High prevalence of Rickettsia helvetica in wild small mammal populations in Germany. Ticks Tick Borne Dis. 2018;9:500-5.

81. Sgroi G, latta R, Lia RP, D'Alessio N, Manoj RRS, Veneziano V, et al. Spotted fever group rickettsiae in Dermacentor marginatus from wild boars in Italy. Transbound Emerg Dis. 2020. https://doi.org/10.1111/tbed.13859.

82. Walker JB. A review of the ixodid ticks (Acari, Ixodidae) occuring in Southern Africa. Onderstepoort J Vet Res. 1991;58:81-105.

83. Horak IG, Cohen M. Hosts of the immature stages of the rhinoceros tick, Dermacentor rhinocerinus (Acari, Ixodidae). Onderstepoort J Vet Res. 2001;68:75-7.

84. Jalovecka M, Sojka D, Ascencio M, Schnittger L. Babesia life cycle - when phylogeny meets biology. Trends Parasitol. 2019;35:356-68.

85. de Mendonça PG. Cross-Genera PCR amplification of DNA from apicomplexan parasites. J Arthropod Borne Dis. 2018;12:321-4.

86. Bosman A-M, Oosthuizen MC, Venter EH, Steyl JCA, Gous TA, Penzhorn BL. Babesia lengau associated with cerebral and haemolytic babesiosis in two domestic cats. Parasit Vectors. 2013;6:128.

87. Margalit Levi M, Nachum-Biala Y, King R, Baneth G. A survey of Babesia spp. and Hepatozoon spp. in wild canids in Israel. Parasit Vectors. 2018;11:150. https://doi.org/10.1186/s13071-018-2715-x.

88. Alho AM, Lima C, Latrofa MS, Colella V, Ravagnan S, Capelli G, et al. Molecular detection of vector-borne pathogens in dogs and cats from Qatar. Parasit Vectors. 2017;10:298. https://doi.org/10.1186/ s13071-017-2237-y.

89. Simking P, Wongnakphet S, Stich RW, Jittapalapong S. Detection of Babesia vogeli in stray cats of metropolitan Bangkok, Thailand. Vet Parasitol. 2010;173:70-5.

90. Vilhena H, Martinez-Díaz VL, Cardoso L, Vieira L, Altet L, Francino O, et al. Feline vector-borne pathogens in the north and centre of Portugal. Parasit Vectors. 2013;6:99. https://doi.org/10.1186/1756-3305-6-99.

91. Vilhena H, Tvarijonaviciute A, Cerón JJ, Vieira L, Pastor J, Silvestre-Ferreira AC. Acute phase proteins response in cats naturally infected with Hepatozoon felis and Babesia vogeli. Vet Clin Pathol. 2017;46:72-6. https://doi. org/10.1111/vcp.12451.

92. Zhang X-L, Li X-W, Li W-J, Huang H-L, Huang S-J, Shao J-W. Molecular evidence of Babesia in pet cats in mainland China. BMC Vet Res. 2019;15:476. https://doi.org/10.1186/s12917-019-2214-0.

93. Millán J, Proboste T, Fernández de Mera IG, Chirife AD, de la Fuente J, Altet L. Molecular detection of vector-borne pathogens in wild and domestic carnivores and their ticks at the human-wildlife interface. Ticks Tick Borne Dis. 2016;7:284-90.

94. Cerqueira-Cézar CK, Thompson PC, Verma SK, Mowery J, Calero-Bernal $\mathrm{R}$, Antunes Murata FH, et al. Morphological and molecular characterization of Sarcocystis arctica-like sarcocysts from the Arctic fox (Vulpes lagopus) from Alaska, USA. Parasitol Res. 2017;116:1871-8. https://doi. org/10.1007/s00436-017-5462-6.

95. Dubey JP, Sykes JE, Shelton GD, Sharp N, Verma SK, Calero-Bernal R, et al. Sarcocystis caninum and Sarcocystis svanai n. spp. (Apicomplexa: Sarcocystidae) associated with severe myositis and hepatitis in the domestic dog (Canis familiaris). J Eukaryot Microbiol. 2015;62:307-17. https://doi.org/10.1111/jeu.12182.

96. Hagner K, Jokinen TS, Lavikainen A, Sukura A. Acute fulminant necrotizing myopathy in a dog caused by co-infection with ultrastructural Sarcocystis caninum and Sarcocystis svanai-like apicomplexan protozoa. Vet Parasitol. 2018;252:153-6. 
97. Pavlásek I, Máca O. Morphological and molecular identification of Sarcocystis arctica sarcocysts in three red foxes (Vulpes vulpes) from the Czech Republic. Parasitol Int. 2017;66:603-5.

98. Ye Y, Liang Y, Hu J, Huang Z, Zhang Y. First isolation of Sarcocystis caninum sarcocysts from two domestic dogs (Canis familiaris) from China. Parasitol Res. 2018;117:3613-8. https://doi.org/10.1007/ s00436-018-6060-y.

99. To KKW, Wong SSY, Poon RWS, Trendell-Smith NJ, Ngan AHY, Lam JWK, et al. A novel Dirofilaria species causing human and canine infections in Hong Kong. J Clin Microbiol. 2012;50:3534-41.

100. Yilmaz E, Fritzenwanker M, Pantchev N, Lendner M, Wongkamchai S, Otranto D, et al. The mitochondrial genomes of the zoonotic canine filarial parasites Dirofilaria (Nochtiella) repens and Candidatus Dirofilaria (Nochtiella) hongkongensis provide evidence for presence of cryptic species. PLoS Negl Trop Dis. 2016;10:e0005028. https://doi.org/10.1371/ journal.pntd.0005028.

101. Yilmaz E, Wongkamchai S, Ramünke S, Koutsovoulos GD, Blaxter ML, Poppert S, et al. High genetic diversity in the Dirofilaria repens species complex revealed by mitochondrial genomes of feline microfilaria samples from Narathiwat, Thailand. Transbound Emerg Dis. 2019;66:389-99. https://doi.org/10.1111/tbed.13033.

102. Ramünke S, de Almeida Borges F, von Son-de Fernex E, von SamsonHimmelstjerna G, Krücken J. Molecular marker sequences of cattle Cooperia species identify Cooperia spatulata as a morphotype of Cooperia punctata. PLoS ONE. 2018;13:e0200390. https://doi.org/10. 1371/journal.pone.0200390.

103. Kuchboev A, Sobirova K, Karimova R, Amirov O, von Samson-Himmelstjerna G, Krücken J. Molecular analysis of polymorphic species of the genus Marshallagia (Nematoda: Ostertagiinae). Parasit Vectors. 2020;13:411. https://doi.org/10.1186/s13071-020-04265-1.

104. Bredtmann CM, Krücken J, Kuzmina T, Louro M, Carvalho LM, von Samson-Himmelstjerna G. Nuclear and mitochondrial marker sequences reveal close relationship between Coronocyclus coronatus and a potential Cylicostephanus calicatus cryptic species complex. Infect Genet Evol. 2019:75:103956.

105. Bredtmann CM, Krücken J, Murugaiyan J, Balard A, Hofer H, Kuzmina TA, et al. Concurrent proteomic fingerprinting and molecular analysis of cyathostomins. Proteomics. 2019;19:1800290. https://doi.org/10.1002/ pmic.201800290.

106. Risch F, Ritter M, Hoerauf A, Hübner MP. Human filariasis—contributions of the Litomosoides sigmodontis and Acanthocheilonema viteae animal model. Parasitol Res. 2021. https://doi.org/10.1007/ s00436-020-07026-2.

107. Olmeda-García AS, Rodríguez-Rodríguez JA, Rojo-Vázquez FA Experimental transmission of Dipetalonema dracunculoides (Cobbold
1870) by Rhipicephalus sanguineus (Latreille 1806). Vet Parasitol. 1993;47:339-42.

108. Olmeda-García AS, Rodríguez-Rodríguez JA. Stage-specific development of a filarial nematode (Dipetalonema dracunculoides) in vector ticks. J Helminthol. 1994;68:231-5.

109. Otranto D, Dantas-Torres F, Brianti E, Traversa D, Petrić D, Genchi C, et al. Vector-borne helminths of dogs and humans in Europe. Parasit Vectors. 2013;6:16. https://doi.org/10.1186/1756-3305-6-16.

110. Hirzmann J, Ebmer D, Sánchez-Contreras GJ, Rubio-García A, Magdowski G, Gärtner U, et al. The seal louse (Echinophthirius horridus) in the Dutch Wadden Sea: investigation of vector-borne pathogens. Parasit Vectors. 2021;14:96.

111. Geraci JR, Fortin JF, Aubin DJ, Hicks BD. The seal louse, Echinophthirius horridus: an intermediate host of the seal heartworm, Dipetalonema spirocauda (Nematoda). Can J Zool. 1981;59:1457-9. https://doi.org/10. 1139/z81-197.

112. Leidenberger S, Harding K, Härkönen T. Phocid seals, seal lice and heartworms: a terrestrial hostparasite system conveyed to the marine environment. Dis Aquat Organ. 2007;77:235-53.

113. Estrada-Peña A, Gray JS, Kahl O, Lane RS, Nijhof AM. Research on the ecology of ticks and tick-borne pathogens-methodological principles and caveats. Front Cell Infect Microbiol. 2013. https://doi.org/10.3389/ fcimb.2013.00029/abstract.

114. Hoarau AOG, Mavingui P, Lebarbenchon C. Coinfections in wildlife: Focus on a neglected aspect of infectious disease epidemiology. PLOS Pathog. 2020;16:e1008790. https://doi.org/10.1371/journal.ppat.10087 90.

115. Heitlinger E, Ferreira SCM, Thierer D, Hofer H, East ML. The intestinal eukaryotic and bacterial biome of spotted hyenas: the impact of social status and age on diversity and composition. Front Cell Infect Microbiol. 2017:7:262.

116. Nacher M. Worms and malaria: blind men feeling the elephant? Parasitology. 2008;135:861-8.

117. Frosch $A E$, John CC. Immunomodulation in Plasmodium falciparum malaria: experiments in nature and their conflicting implications for potential therapeutic agents. Expert Rev Anti Infect Ther. 2012;10:134356. https://doi.org/10.1586/eri.12.118.

118. Penzhorn BL, Oosthuizen MC. Babesia species of domestic cats: molecular characterization has opened Pandora's Box. Front Vet Sci. 2020. https://doi.org/10.3389/fvets.2020.00134/full.

\section{Publisher's Note}

Springer Nature remains neutral with regard to jurisdictional claims in published maps and institutional affiliations.
Ready to submit your research? Choose BMC and benefit from:

- fast, convenient online submission

- thorough peer review by experienced researchers in your field

- rapid publication on acceptance

- support for research data, including large and complex data types

- gold Open Access which fosters wider collaboration and increased citations

- maximum visibility for your research: over $100 \mathrm{M}$ website views per year

At BMC, research is always in progress.

Learn more biomedcentral.com/submissions 